\title{
Signature Analysis Utilizing a Dynamic Molten Salt Reactor Model for MC\&A
}

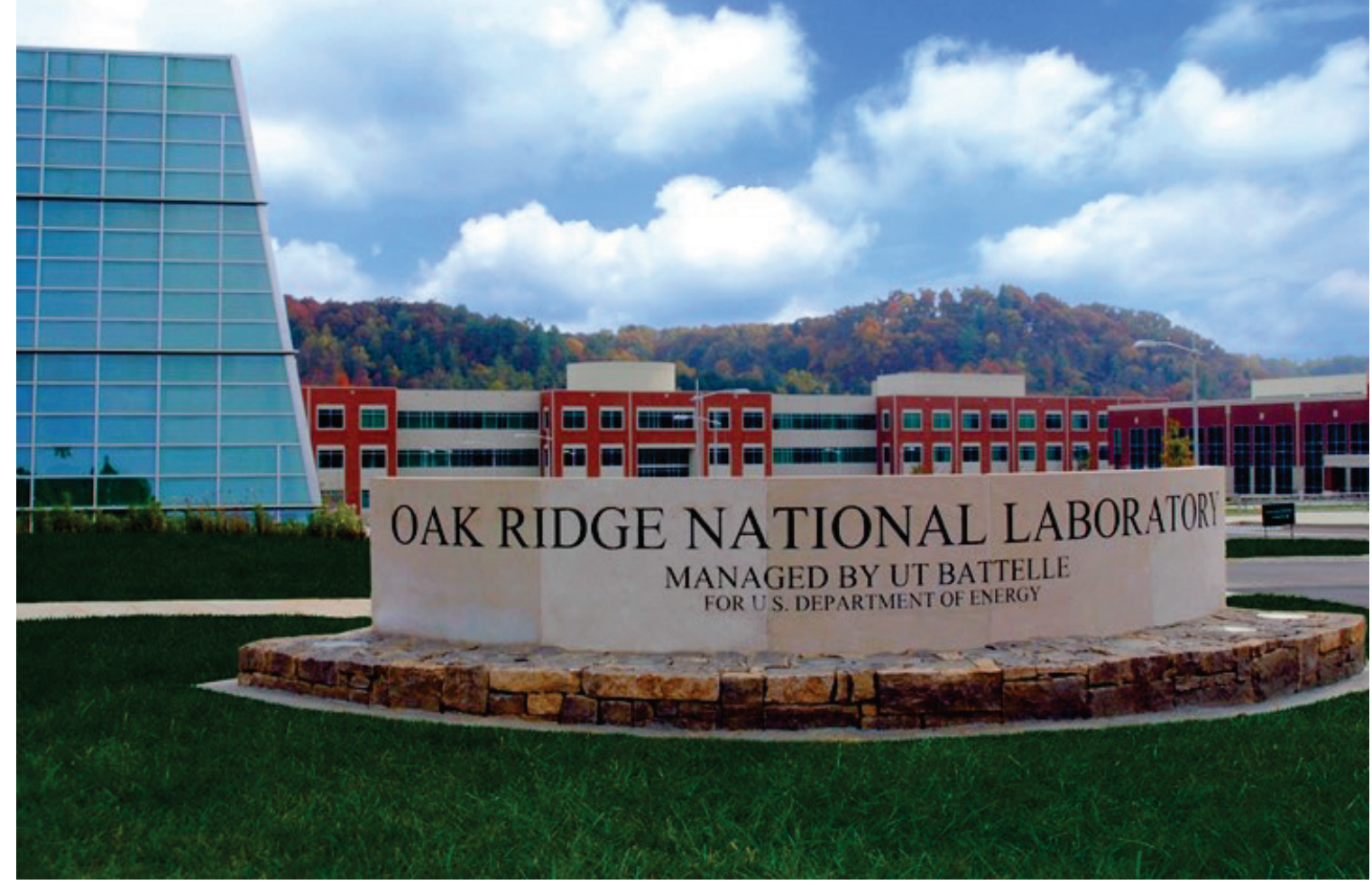

Michael P. Dion

M. Scott Greenwood

Karen Hogue

Sean O'Brien

Logan Scott

Greg Westphal

June 2021 


\section{DOCUMENT AVAILABILITY}

Reports produced after January 1, 1996, are generally available free via US Department of Energy (DOE) SciTech Connect.

Website www.osti.gov

Reports produced before January 1, 1996, may be purchased by members of the public from the following source:

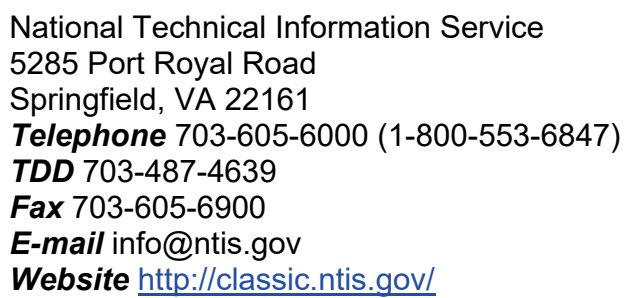

Reports are available to DOE employees, DOE contractors, Energy Technology Data Exchange representatives, and International Nuclear Information System representatives from the following source:

Office of Scientific and Technical Information

PO Box 62

Oak Ridge, TN 37831

Telephone 865-576-8401

Fax 865-576-5728

E-mail reports@osti.gov

Website http://www.osti.gov/

This report was prepared as an account of work sponsored by an agency of the United States Government. Neither the United States Government nor any agency thereof, nor any of their employees, makes any warranty, express or implied, or assumes any legal liability or responsibility for the accuracy, completeness, or usefulness of any information, apparatus, product, or process disclosed, or represents that its use would not infringe privately owned rights. Reference herein to any specific commercial product, process, or service by trade name, trademark, manufacturer, or otherwise, does not necessarily constitute or imply its endorsement, recommendation, or favoring by the United States Government or any agency thereof. The views and opinions of authors expressed herein do not necessarily state or reflect those of the United States Government or any agency thereof. 
Nuclear Nonproliferation Division

\title{
SIGNATURE ANALYSIS UTILIZING A DYNAMIC MOLTEN SALT REACTOR MODEL FOR MC\&A
}

\author{
Michael P. Dion \\ M. Scott Greenwood \\ Karen Hogue \\ Sean O'Brien \\ Logan Scott \\ Greg Westphal
}

June 2021

\section{Prepared by}

OAK RIDGE NATIONAL LABORATORY

Oak Ridge, TN 37831-6283

managed by

UT-BATTELLE LLC

for the

US DEPARTMENT OF ENERGY

under contract DE-AC05-00OR22725 



\section{CONTENTS}

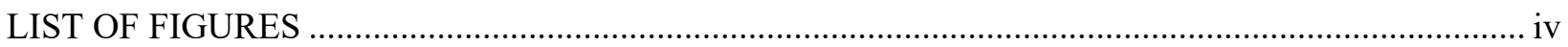

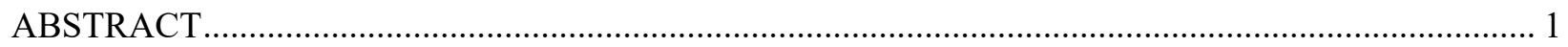

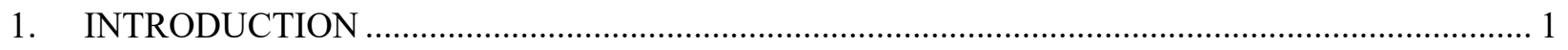

1.1 DYNAMIC SIGNATURE INVENTORY SOLUTIONS …............................................ 3

2. MODEL OF THE MOLTEN SALT DEMONSTRATION REACTOR (MSDR) ............................. 4

2.1 MSDR MODEL MOTIVATION ..................................................................................... 4

2.2 SIMULATION AND MODELING OF ISOTOPIC CONCENTRATIONS ........................... 4

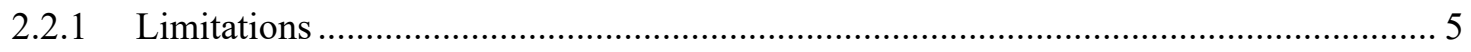

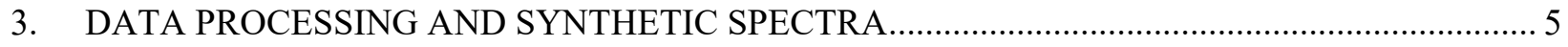

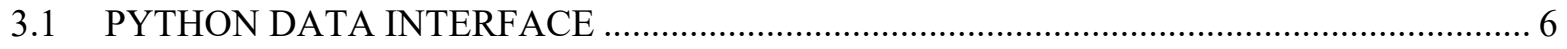

3.2 GAMMA DETECTOR RESPONSE AND ANALYSIS CODE .................................... 6

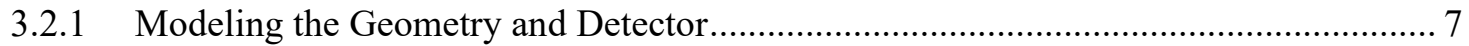

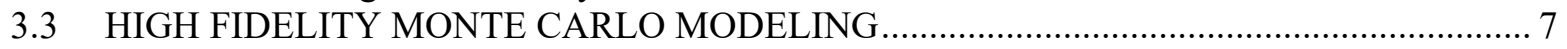

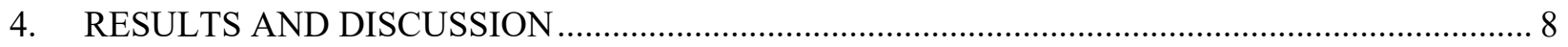

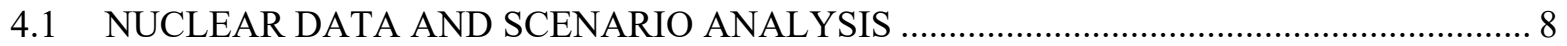

4.2 GENERALIZED ISOTOPIC CONCENTRATIONS ........................................................ 9

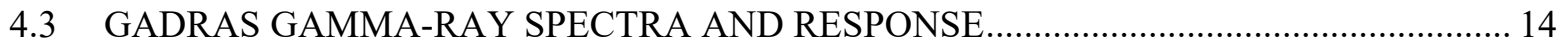

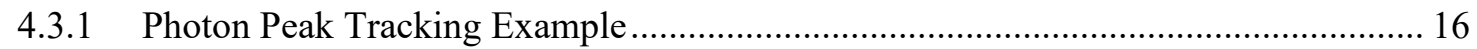

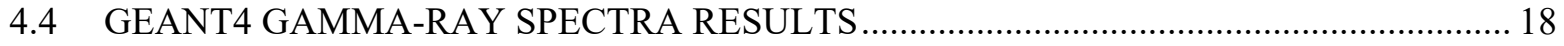

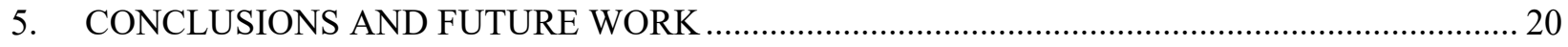

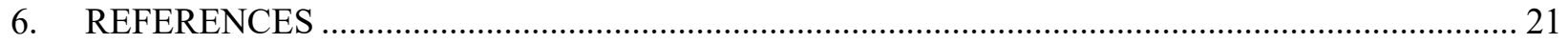




\section{LIST OF FIGURES}

Figure 1. Overview of the data processing steps to generate synthetic spectra from the TRANSFORM data file.

Figure 2. A side and top-down view of the geometry definition of the pipe from the reactor core to the PHX.

Figure 3. The relative difference of the isotope cumulative fission yields comparing the base scenario $(50 \%-50 \%$ thermal fission split) to scenario $3(70 \%-30 \%$ thermal fission split).

Figure 4. Normalized power of the three scenarios.

Figure 5. Normalized activities for the rare earth elements, group 1, for the three scenarios for the pipe from the reactor core to the PHX.

Figure 6. Normalized activities for $\mathrm{Sr}, \mathrm{Y}, \mathrm{Zr}$, and $\mathrm{Nb}$, group 2, for the three scenarios for the pipe from the reactor core to the PHX.

Figure 7. Normalized activities for $\mathrm{Mo}, \mathrm{Ru}, \mathrm{Rh}, \mathrm{Sn}, \mathrm{Sb}$, and Te, group 3, for the three scenarios for the pipe from the reactor core to the PHX

Figure 8. Normalized activities for the noble gases, I, Br, and Cs, group 4, for the three scenarios for the pipe from the reactor core to the PHX

Figure 9. Synthetic photon spectra for the three scenarios ( 1 is black, 2 is teal, and 3 is blue). 15

Figure 10. Relative difference of photon count rate comparing scenarios 2 and 3 to scenario 1 .

Figure 11. Photon peak counts resulting from the peak tracking GADRAS analysis for ${ }^{99} \mathrm{Mo}$.

Figure 12. Photon peak counts resulting from the peak tracking GADRAS analysis for ${ }^{140} \mathrm{La}$.

Figure 13. Ratio of the $1,596 \mathrm{keV}$ peak counts of ${ }^{140} \mathrm{La}$ to the $529 \mathrm{keV}$ photon peak counts of ${ }^{99}$ Mo for the three scenarios.

Figure 14. Simulated number of decays for the fission product isotopes after downscaling the activities from the primary fuel circuit.

Figure 15. Energy broadened histograms of the three scenarios after physics transport modeling with Geant4.

Figure 16. Close-up of the region around $1,000 \mathrm{keV}$ in Figure 15 and the $1,131 \mathrm{keV}$ gamma-ray of ${ }^{135} \mathrm{I}$. 


\begin{abstract}
Moving from traditional fixed fuel nuclear reactor systems to a mobile, dynamic fuel system that has dissolved special nuclear material in a molten salt is a paradigm shift in several respects. One major consideration is how to develop effective nuclear material controls and accounting for these novel reactor systems. The Molten Salt Reactor Experiment is one example of a critical molten salt system and provided a significant reference library based on the documented effort. But it was low thermal power that was not intended to reflect a commercial scale electricity production design. Therefore, to facilitate and assist vendors with domestic licensing considerations, research is underway to identify methods that could be used for domestic safeguards ${ }^{1}$ approaches for these novel reactor systems. This research presents the results of a signature analysis of data generated from three simulated scenarios using the molten salt demonstration reactor model defined in the Transient Simulation Framework of Reconfigurable Modules. Each scenario provides 1 hour isotope inventories over a 180 day period. The scenarios investigated provide test cases to examine if direct gamma-ray spectroscopy of the fuel can be used to identify changes comparing a base case (no reactivity control and fixed fission contribution) to an insertion of reactivity (10 pcm no change in fission composition) and a change in fission composition. The analysis demonstrates that monitoring the total count rate in a highly collimated high-resolution photon energy spectrum is sensitive to perturbations imposed into the reactor model. The total photon count rate changes $\approx 2 \%$ for the fission composition change and $\approx 4.5 \%$ for the reactivity insertion compared to the base case. However, both scenarios show an increase in the total photon count rate. The total photon count rate can be used to identify changes due to power (number of fissions) but not due to a change in the material undergoing fission. To distinguish between the two cases of increased power, the photon spectrum would require an intensive analysis technique. A photon peak count rate ratio analysis could be used to identify changes in the fissile material fission generation in the core through identification of a static peak that shows little variation to the source of fission and a highly varying peak. The photon peak strength will ultimately be determined by the isotope's fission yield. A preliminary analysis investigating the coupling of the isotope's fission yield and its concentration in the fuel salt derived from the modeling has been performed. A ratio analysis of the photon peak count rates of ${ }^{140} \mathrm{La}$ to ${ }^{99} \mathrm{Mo}$ demonstrated that the reactivity insertion creates a distinct difference in the ratio compared to the fission composition change scenario.
\end{abstract}

\title{
1. INTRODUCTION
}

Molten salt reactor (MSR) concepts are being pursued by vendors for domestic and international deployment. In particular, liquid fueled MSRs may offer many advantages compared to light water reactors and they will likely require novel safeguard methodologies and technologies. Novel material control and accounting (MC\&A) techniques will likely play a critical role in domestic safeguards approaches to deter and detect theft of special nuclear material (SNM) from a facility [1]. MSR designs and operations are significantly different from the current commercial nuclear reactor fleet. For example, MSRs are operated at normal atmospheric pressure and therefore are not expected to require as robust containment structures as light or heavy pressurized water reactors (though they will still require biological shielding and other safety measures for dose reduction). In addition, MSRs operate at higher temperatures, which improves electricity generation efficiency and allows for additional process heat applications. MC\&A approaches for nuclear material in MSRs will greatly differ from traditional fixedfuel commercial technology, which is mainly due to the mobility of the fissile fuel in the molten salt compared to material being contained in fixed distinct items (e.g., pellets in fuel rods). As the MSR

\footnotetext{
${ }^{1}$ The US Nuclear Regulatory Commission defines Domestic Safeguards as the physical protection of facilities and/or special nuclear material as well as material control and accounting for special nuclear material https://www.nrc.gov/security/domestic.html.
} 
designs advance and become closer to commercialization, tools and methods must be developed to assist in the development of an effective and efficient MC\&A plan to meet domestic safeguards objectives for SNM that can be incorporated into the design. Early considerations for integration of new techniques needed to monitor the SNM in an MSR facility may reduce costs, expedite licensing, and promote best safeguards and security practices. Current research to identify MC\&A objectives, existing and new measurement techniques and technologies, potential measurement locations and their signatures, and correlations of those signatures to quantities and locations of fissile material in the system are underway at Oak Ridge National Laboratory. This research focuses on supporting development of MC\&A approaches for MSR designs to meet US domestic safeguards objectives (i.e., detect or deter theft or diversion of SNM). This is a requirement for licensing in the United States as the Nuclear Regulatory Commission requires licensees to develop and maintain MC\&A programs during the application process and for operation. The outcomes of this research are also relevant for international nuclear safeguards to support the International Atomic Energy Agency in development of safeguards approaches to ensure all nuclear material at facilities under safeguards agreements is used for peaceful purposes.

A dynamic, system-level modeling tool, the Transient Simulation Framework of Reconfigurable Modules (TRANSFORM), is being used to investigate operational conditions and their influence on fuel composition, and system response using a validated model of the Molten Salt Demonstration Reactor (MSDR) [2]. The MSDR design is a liquid-fueled, graphite-moderated MSR design that uses a ${ }^{7} \mathrm{LiF}_{-} \mathrm{BeF}_{2}$ salt with $4.95 \%$ enriched ${ }^{235} \mathrm{U}$ [2] in fluoride form. The MSDR design does not include online chemical separation of fuel salt to extract fissile material, but it does contain other system components including noble gas removal to predominantly prevent ${ }^{135} \mathrm{Xe}$ poisoning. This report presents research results using TRANSFORM to model the MSDR and analyze various measurement locations, radioisotope concentrations, and the dynamic behavior of certain key isotopes over an operational history. Three operational scenarios were modeled and the processed and analyzed results are described in this report. Each operational scenario was run for $180 \mathrm{~d}$ with $1 \mathrm{~h}$ solution intervals. The following scenarios were simulated:

1. Baseline-A steady-state* operation with no reactivity control. The fission contribution that generated power in the model is fixed at $50 \%-50 \%{ }^{235} \mathrm{U}-{ }^{239} \mathrm{Pu}$ thermal fission.

2. Reactivity insertion-At $90 \mathrm{~d}$, a change in reactivity (10 percent mille ( $\mathrm{pcm}))$ was introduced. Fissile material composition is the same as the baseline scenario. A reactivity variation during operation of a MSR could be due to control rod movement, refueling, and other molten salt processing.

3. Fissile composition change-At $90 \mathrm{~d}$, the fission contribution that generated power in the model was changed from the baseline to $70 \%-30 \%{ }^{235} \mathrm{U}-{ }^{239} \mathrm{Pu}$ thermal fission. This abrupt change does not represent a likely operation scenario in an MSR, but it provides a useful means to evaluate how the fission product isotopes respond.

Each operational scenario was simulated using TRANSFORM for the MSDR model. The output data from each simulation contained isotopic inventory data for 91 fission products at multiple (user defined) locations in the model. The grouping of other broad elemental groups is also available, and a description of these groups and the priority given to the 91 fission products is discussed in Greenwood, et al. [3]. The concentrations are provided for the time steps specified - in this report for each hour of the $180 \mathrm{~d}$ simulation. This data was processed, and a spectral photon gamma-ray analysis was performed. This allowed the fission product isotopes to be characterized based on their sensitivity to the changes presented

\footnotetext{
* The term steady state is used here to indicate there was no method imposed by the user to control reactivity during the simulation. Note, MSRs never truly achieve a steady state.
} 
in scenarios 2 and 3 and assess how these various perturbations affect the fission product gamma signatures. This methodology allows the identification of indicators and measurement locations pertaining to the modeled operational changes in the MSDR model. This research and analysis will allow an evaluation of how gamma-ray spectroscopy could be used in a broader MC\&A program, specifically allowing optimization of effective measurement locations and frequencies to monitor operation and identify diversion of SNM. In addition, this analysis provides a benchmark to compare to the software development changes that are planned for TRANSFORM under the overall research project, which includes expanding the fission product isotope list and incorporating fissile material burnup and transmutation.

\subsection{DYNAMIC SIGNATURE INVENTORY SOLUTIONS}

The flowing salt within the primary fuel loop of an MSR contains radioisotopes from fission of the fissile material and activation products resulting from various interactions of neutrons within the fuel salt. These radioisotopes are direct indicators of the history and state of reactor operations. Changes in the isotopics might be used to indicate abnormal operations, including diversion of SNM. This research presents the development of analysis and modeling methods to understand how the potential signatures of these radioisotopes could be identified using gamma spectroscopy based on a model of the MSDR and simulations performed with TRANSFORM. If signatures and correlations are discovered, the technique could be integrated into a broader MC\&A program for MSRs.

One proposed method is to continuously measure the gamma-ray spectrum of the fuel salt and identify radioisotopes at specific points within the MSR process streams. The ability to model and simulate the isotopic concentrations of an MSR at the system-component level will enable conclusions to be made about the utility of the proposed measurements and how they could be used in a MC\&A monitoring approach. This research attempts to address the following questions used in direct monitoring during operation:

- What isotopes provide useful indicators of diversion of SNM?

- Does the signature deviate enough (from expectations) to be informative/measurable?

- What signatures provide information to monitor key changes in the primary fuel isotopics?

- Is full spectrum analysis required or could peak tracking for specific isotopes be sufficient?

- What detector-specific requirements (e.g., resolution, collimation, efficiency) are needed?

The ideal measurement locations, perhaps at multiple points, must also be determined. Measuring at the reactor vessel may be impractical because of the overwhelming neutron and gamma radiation field. Measuring in high count-rate environments could present challenges with instrumentation including damage to the radiation detection equipment, large dead time and or pulse pileup that would make analysis difficult or impossible. To accommodate potential count rate complications, the detection system could be placed far away from the measurement location, or fuel salt could be drawn away from the reactor core using a separate flow stream, which would result in a lower radiation field, but emissions from shorter lived isotopes or isotopes with lower specific activity could be overlooked. Therefore, there will likely be a tradeoff between geometric bounds of the monitoring equipment and the available signatures based on the configuration. The radiation detector (e.g., $\mathrm{NaI}(\mathrm{Tl})$ ) or high purity germanium (HPGe), must have sufficient energy resolution to distinguish gamma-ray spectral lines of interest from background counts or other interfering peaks. The detectors may require significant collimation and shielding to obtain a useful spectrum but must be developed in way to not remove any key gamma-ray signatures of interest. Understanding the influence of shielding and collimation becomes more important if low energy ( $\approx 200 \mathrm{keV}$ or less) gamma-ray photons are identified as useful indications of fuel composition. However, note that the objective of this report is to investigate the modeled data for various scenarios to determine if there are signatures that are indicative of operational changes. So, although 
detector and geometrical details are important, the parameters used in this report to generate spectra may not be ideal and would require an additional sensitivity and optimization study.

\section{MODEL OF THE MOLTEN SALT DEMONSTRATION REACTOR (MSDR)}

TRANSFORM is a dynamic modeling suite developed at Oak Ridge National Laboratory that allows for system-level simulations of complex nuclear systems. In fact, it was developed under the MPACT MSR Campaign to model the inherent dynamic nature of MSR systems. The package is written in the objectoriented and open-source Modelica language [4], and a Modelica graphical user interface (GUI) Dymola was used [5]. Further development has allowed the dynamic flow loops to be coupled with various reactor kinetics and feedback mechanisms. This allows for a multiphysics model of an MSR that generates timedependent concentrations of radioisotopes and other data (i.e., temperatures, pressures, etc.) within the modeled reactor system.

The MSDR is a $750 \mathrm{MW}_{\text {th }}$, graphite moderated (thermal spectrum) $4.95 \%$ enriched uranium MSR model based largely on documented conceptual designs developed at Oak Ridge National Laboratory in the early 1970s [6]. It is a liquid-fueled, FLiBe salt design with a primary fuel circuit consisting of the reactor core, piping, main salt pump, off-gas system, and primary heat exchanger (PHX). The heat is transferred through the PHX to the primary coolant loop. The primary coolant loop is FLiBe salt without fuel. Other details related to the specifics of heat discharge and balance of plant of the MSDR model can be found in [3].

\subsection{MSDR MODEL MOTIVATION}

The MSDR model shares many features and system components (off-gas removal, decay heat removal tanks, etc.) that are present in many current MSR designs. The model is of commercial scale power, and there are no proprietary information boundaries present that would cause complications to replicate those specific features in a working model. The MSDR can be used to capture many of the gross operational characteristics of a liquid-fueled fluoride salt design. For the purposes of the research proposed here, the analysis of isotopic concentrations and their respective resulting gamma-ray spectra, it is a convenient, accurate model to explore and provide guidance when more detailed vendor-specific designs can be obtained (in the future).

\subsection{SIMULATION AND MODELING OF ISOTOPIC CONCENTRATIONS}

The current implementation of TRANSFORM tracks fission products in the fuel-salt matrix as trace components. These trace substances are homogenously distributed, mass-weighted components that do not contribute to the mass balance equations in the solution. These trace substances follow the salt matrix indefinitely as chemistry and potential plate-out is not implemented at this time. If more complicated scenarios are warranted, such as sparging systems to remove insoluble gases from a liquid stream, that can be added in the future as needed. In addition, tracking other components of interest (e.g., SNM, fertile material) can be added to the model. System components, like the reactor core and piping that carries the fuel-salt mixture, was discretized into nodes to allow the user to extract data on a finer spatial distribution and gain insight into the transport of the fluid through the primary fuel loop for example. Because the system components are discretized, the trace substance concentrations (i.e., the fission products) and other output variables are solved at these node locations. The desired output variables can be analyzed at the inlet or outlet boundary of a component or can be tallied and spatially averaged over the volume of a component node. Therefore, inventories of the fission products are available at these discretized points in the model, which allows even further insight into their transport and use in radiometric measurement scenarios. 


\subsubsection{Limitations}

The data analyzed in this report is based on the modified point reactor kinetics model [7] of the MSDR. There is a severe processing expense with tracking the entire suite $(\approx 2,000)$ of fission products. Therefore, this model is based on a reduced set of fission products (91) that allowed the modeling to be performed on a personal computer in reasonable computational time frames. Even with this reduced set of tracked isotopes, this model still enabled investigation of how fission product concentrations change over time and provided insight into those key isotopes of interest that affect reactivity and feedback. However, this reduced isotope list may not provide the complete radiometric response especially when gamma-ray spectra are based on those reduced isotopic inventories. This could be particularly important for very short-lived isotopes or isotopes that become more prominent in the fuel salt after sparging/off-gas removal. Future work under this research will address these limitations. In addition, the fissile material is not tracked in the salt and because of the point kinetics model used, the power generated from the model is based on a stationary fission split defined by the user. Although this may not accurately represent all features of an operational reactor, it does allow research into signatures or variations in isotope concentrations when specific changes to the model are imposed. Therefore, this analysis focuses on understanding correlations of isotope concentrations and photon peak changes using the three scenarios previously described: baseline (no change), reactivity insertion, and a significant change in the fission split driving the power of the model.

\section{DATA PROCESSING AND SYNTHETIC SPECTRA}

TRANSFORM generates time-dependent isotopic concentrations present in the salt at user defined locations in the reactor model, such as at the core, piping (e.g., to the PHX), and decay tanks for the offgas fission product isotopes. The fission products generated during operation of the MSR are present in the fuel salt and undergo radioactive decay during their transport around the primary fuel loop. During radioactive decay, they emit photons resulting from nuclear and atomic deexcitations. The nuclear deexcitations result in the emission of gamma-rays and are isotope specific signatures. This research is investigating the utility of these signatures for MC\&A purposes, using TRANSFORM as a modeling tool to generate fission product inventories. Therefore, a code tool kit was developed to parse the output TRANSFORM data file structure and develop synthetic gamma-ray energy spectra from the isotopic inventories. The GADRAS (Gamma Detector Response and Analysis Software) application programming interface (API), mediated by Python, was employed to perform this task. This tool kit (a) provides a means of data analysis to inform the MC\&A approach, (b) can be used to identify signatures that may be reliable indicators of diversion of material or misuse of the facility, and (c) helps develop data-informed design criteria for detection equipment specific for use in MSRs. In addition, since TRANSFORM can provide isotope inventories at the specific reactor components (e.g., pump bowl, fuel cell) and at specific locations (e.g., primary fuel loop pipe sections), this data and analysis method can be used to select and optimize the measurement locations for the proposed MC\&A approach. The developed approach to process the TRANSFORM data structure and generate synthetic spectra is shown in Figure 1. 


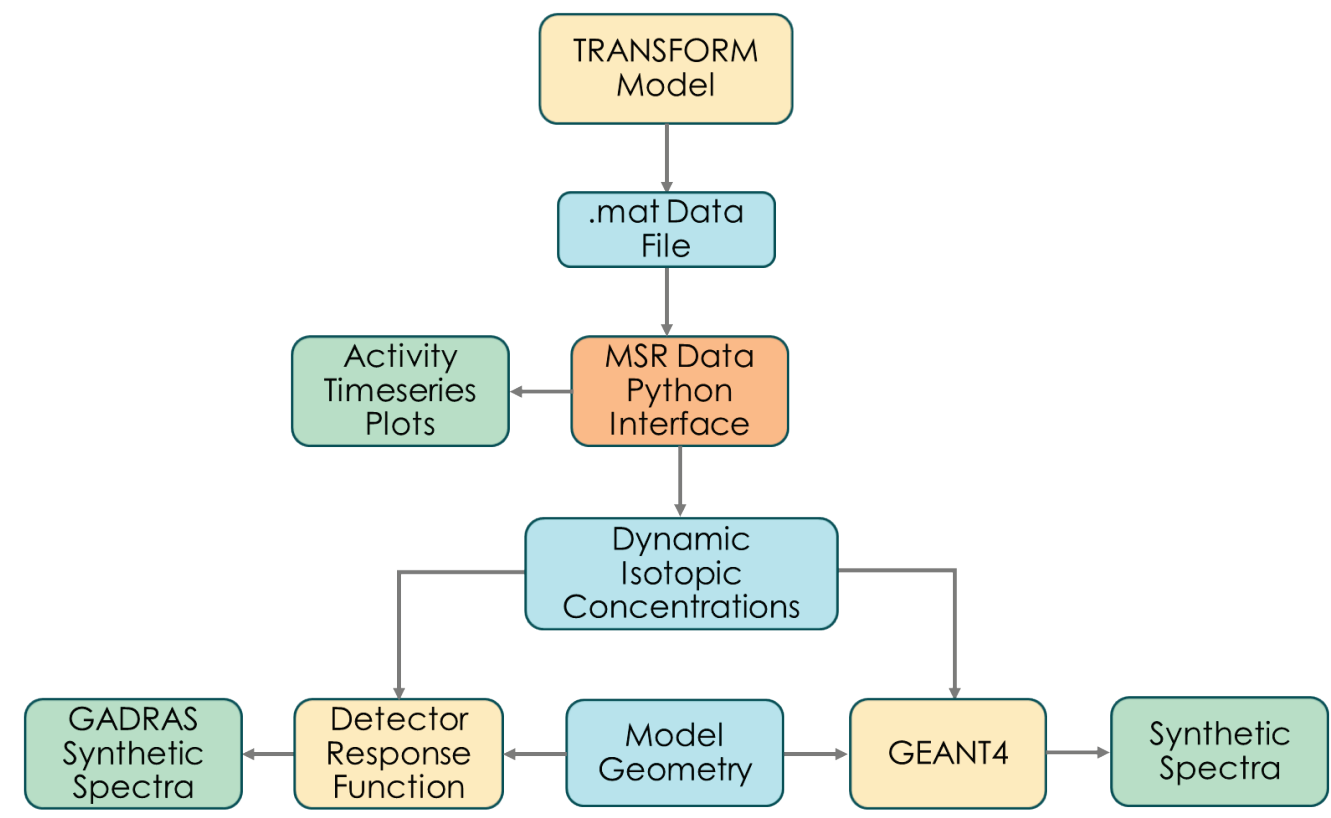

Figure 1. Overview of the data processing steps to generate synthetic spectra from the TRANSFORM data file.

\subsection{PYTHON DATA INTERFACE}

A Python interface, between TRANSFORM and the GADRAS API, is used to extract and process the TRANSFORM/Modelica output files (*.mat) generated during the MSR simulation. The BuildingsPy Python module was used to parse the data structure [8]. The Python interface enables access to all the parameters of the TRANSFORM MSDR simulation, including temperatures, flow rates, and isotopic concentrations at all user defined locations. It can also generate the time-dependent source terms at locations within the MSDR model and directly evaluate the isotopic behavior before generating synthetic spectra. The inputs to the Python script are the variable names defined in the TRANSFORM model (e.g., pipe, tank), the isotopes of interest from the dictionary, and an integration time. The integration time can be different than the solution intervals used for the TRANSFORM simulation, providing flexibility to the user. The Python interface produces a file containing a list of time-dependent isotopic activities for the selected fission product isotopes. This data is further processed by a new $\mathrm{C \#}$ library implementing the GADRAS API or used for high fidelity modeling in GEANT4 [9].

\subsection{GAMMA DETECTOR RESPONSE AND ANALYSIS CODE}

The GADRAS API was used to streamline the processing of data and allow user flexibility to generate synthetic spectra. GADRAS excels at quickly simulating radiometric spectra and allows users to rapidly explore source and measurement configurations. This $\mathrm{C \#}$ framework is currently implemented as an executable (useful for batch processing) and as a GUI to allow the user to easily make changes to the detector environment and select other data files. The GADRAS API enables users to implement the capabilities available through the GADRAS GUI into stand-alone code or programs. The GUI implementation can be used with GADRAS to allow real-time viewing and evaluation of the resulting spectrum, as well as adjusting the detector, source model, and measurement parameters. This research used the GADRAS API in a GUI application that accepts the input isotopic source terms from TRANSFORM after processing with the Python interface. A geometric model of the MSDR component that contains the fission product sources, a detector, and the simulated measurement parameters (e.g., dwell time, distance to detector, energy calibration) were defined and modified using this platform. This 
library injects the source term into a model of the MSDR location, a measurement specification (e.g., distance, measurement time), and a detector specification to generate a synthetic detector spectrum for each time step of the TRANSFORM solution steps.

\subsubsection{Modeling the Geometry and Detector}

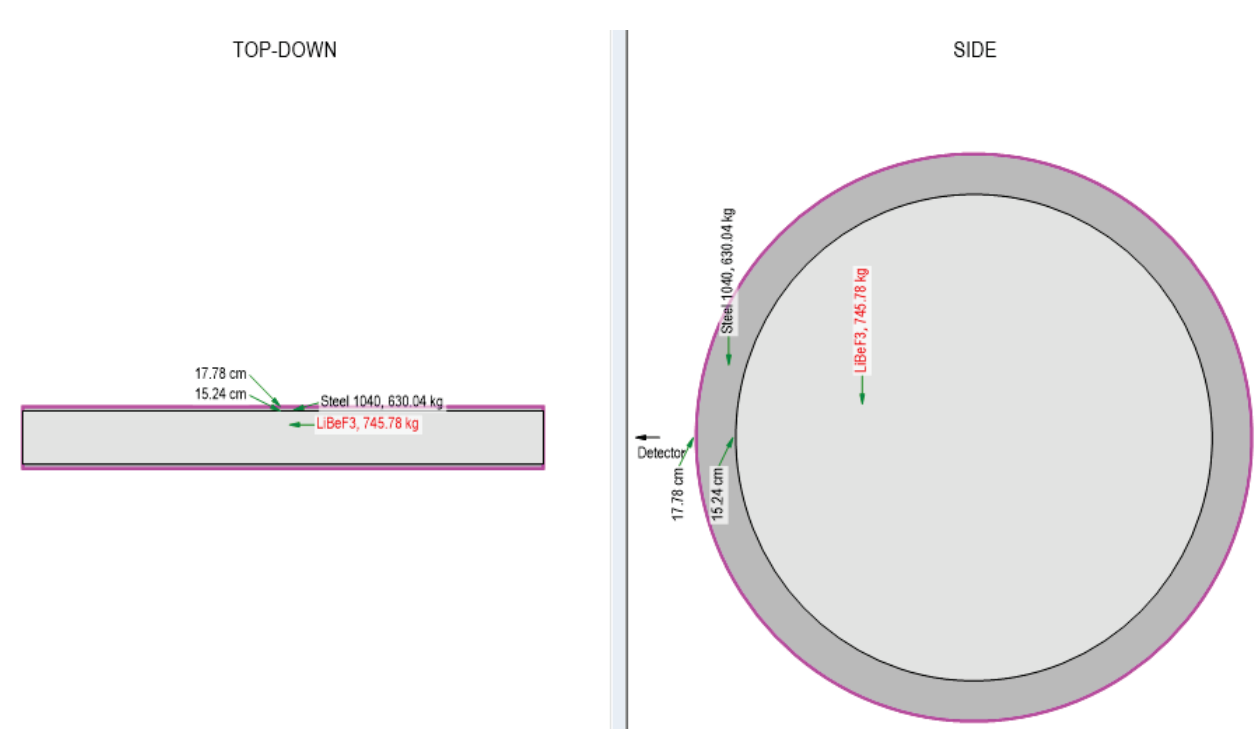

Figure 2. A side and top-down view of the geometry definition of the pipe from the reactor core to the $\mathrm{PHX}$.
Isotopic concentrations were taken from the pipe from the reactor core leading to the PHX and defined in GADRAS (Figure 2). The material in the MSDR would be a steel nickel alloy (Hastelloy N) but for simplicity, the pipe material in GADRAS was steel. A detector with collimation and shielding was defined to view a pipe with similar size and construction as defined in the

TRANSFORM MSDR model. The salt matrix was defined as a custom material in GADRAS with weight percent of $\mathrm{F}(12.35 \%), \mathrm{Be}(78.13 \%)$, and $\mathrm{Li}(9.52 \%)$. Each fission product isotope contained in the time step of the TRANSFORM solution is inserted as a trace source (all 91) in the salt matrix contained in the pipe using GADRAS. Trace sources in GADRAS do not alter the medium they are present in and are homogenously distributed in that medium. The detector was a modification of one predefined in GADRAS - a cryo-cooled HPGe with $78 \%$ relatively efficiency at $1,332 \mathrm{keV}$. A significant lead collimator ( $1 \mathrm{~m}$ in length with a $0.16 \mathrm{~cm}$ diameter opening) was defined in GADRAS and reduced the efficiency to $2 \times 10^{-3} \%$ at $1,332 \mathrm{keV}$. The collimator approximates the dimensions used in the measurement campaign of the Molten Salt Reactor Experiment (MSRE) [10]. The collimator is defined using several GADRAS detector parameters including an inner and outer attenuator thickness, material, and porosity; collimator extents (including side and back shielding) and effective borehole diameter; and an efficiency scalar to get the correct uncollided flux while still collecting the scatters within the collimator. The detector-to-pipe standoff distance was $1 \mathrm{~m}$. This geometry tended to produce count rate (i.e., dead time) counting results that would maintain confidence in the measured spectra (i.e., less than $\approx 30 \%$ dead time).

\subsection{HIGH FIDELITY MONTE CARLO MODELING}

Geant4 v10.6.02 and the radioactive decay module v5.4 was used for high fidelity Monte Carlo physics transport simulations [9]. GADRAS is extremely useful, but there are limitations to the software, including some geometrical situations that can only be studied using Monte Carlo techniques. Therefore, having access to both tool kits for simulations and modeling gamma-ray spectra from the isotopic concentrations generated from TRANSFORM will be useful once detector sensitivity and shielding are considered. The geometry used in the GADRAS model was reproduced in Geant4. The Python interface 
used to process and parse the TRANSFORM output file is used to generate a Geant4 input macro file. This macro file contains a list of all (radioactive) fission product isotopes and their activity found through the TRANSFORM simulation. The isotopic activities are scaled to reflect the geometry and sample volume used in the simulation. The radioactive decay module used in Geant4 allows the user to define an isotope as an ion, and it then generates particle $\left(\alpha, \beta^{-}, \gamma\right.$, etc.) emission based on its decay properties. The ions are defined in a volume that represents the simulation source term. Each particle resulting from radioactive decay is propagated and can be extensively tracked. A sensitive volume is defined that represents the detector media (HPGe, $\mathrm{NaI}(\mathrm{Tl})$, etc.) being investigated in the model. This allows the energy deposited by each particle in the sensitive volume to be stored for further analysis. In addition, dose can be simulated by placing a human phantom in proximity to the source and storing the resulting data.

\section{RESULTS AND DISCUSSION}

The output files generated from TRANSFORM for each scenario contain data various parameters (e.g., pressure, temperature, and isotope activity) at the user defined locations in the MSDR model. These data files were parsed to generate a dictionary of key terms that allow the user to rapidly access and analyze the data. Each scenario output file contained 4,320 entries with information of each $1 \mathrm{~h}$ step over the $180 \mathrm{~d}$ solution period. The data was analyzed to identify indications (total photon count rate, photon peak variations, etc.) of the reactivity and fissile composition changes imposed in the model. For the analysis presented here, the isotope concentrations were scaled as needed and input into GADRAS to produce photon energy spectra. In addition, trend plots of the total power of each scenario over time, and the isotopic concentrations were investigated for indications of the conditions of the three scenarios.

\subsection{NUCLEAR DATA AND SCENARIO ANALYSIS}

In a traditional fixed fuel nuclear reactor system, the fission product decay chains will come into an equilibrium condition when the production (fission) equals the loss (radioactive decay). Generally, MSRs may not demonstrate equilibrium conditions in some of the fission product chains because of the off-gas removal system and other proposed chemical separation scenarios. However, even with (noble) gas removal the observed fission product isotope concentration changes should demonstrate a slowly varying, nearly steady-state condition once power and reactivity are stabilized. The three scenarios are identical up to the midpoint of the $180 \mathrm{~d}$ simulation when the change of scenarios 2 and 3 is imposed. The reactivity insertion in scenario 2 will cause an increase in power and, therefore, fissions, so there is an increase in the amount of some of the fission product isotopes present. An increase in total count rate or counts present in regions of interest or peak areas would be present following the reactivity insertion in scenario 2 . This change could be observed by analyzing several regions of interest or photon peak areas over time steps - comparing a post-analysis with a prior analysis to detect count rate changes. For scenario 3, the composition of fission that is determining power generation in the model is changed in a way to simulate a change in the fissile material composition of the fuel salt. A distinct difference in the quantities of fission product isotopes produced based on the fission yield distribution of the respective material and incident neutron spectrum is expected. This change could be analyzed by comparing ratios of photon peak areas as opposed to peak area count rates.

To investigate the fuel salt composition changes and fission product isotope production, the cumulative fission yields of ${ }^{235} \mathrm{U}$ and ${ }^{239} \mathrm{Pu}$ at thermal neutron energy were analytically compared for a reduced list of the 91 isotopes available. The reduced list omitted stable isotopes and isotopes with a half-life greater 
than $35 \mathrm{y}$, as listed on the $\mathrm{x}$-axis of Figure 3 . An isotope's abundance* in the fuel salt, $R_{j}$, due to a multicomponent fission source, $f$, is the weighted sum.

$$
R_{j}=\sum_{i}^{n} w_{i} \times f_{i, j}
$$

Here, $w_{i}$ is the weighting factor or fractional fission contribution and $\mathrm{f}_{\mathrm{i}, \mathrm{j}}$ is the cumulative fission yield ${ }^{\dagger}$ [11] of isotope, $\mathrm{j}$, for the fission component, $\mathrm{i}$ (here i could be ${ }^{235} \mathrm{U}_{\mathrm{th}},{ }^{235} \mathrm{U}_{\mathrm{f}},{ }^{239} \mathrm{Pu}_{\mathrm{th}}$, etc.). As an example, the abundance calculation is shown for the base case $\left(w_{235 \text { Uth }}=0.5\right.$ and $\left.w_{239 P u t h}=0.5\right)$, and the result is provided for scenario $3\left(w_{235 \text { Uth }}=0.7\right.$ and $\left.w_{239 P u t h}=0.3\right)$ for ${ }^{144} \mathrm{Ce}$.

$R_{144}$ Ce $_{\text {base }}=\left(0.5 \times f_{235_{U_{t h}}}\right)+\left(0.5 \times f_{239_{P u_{t h}}}\right)=(0.5 \times 0.054996)+(0.5 \times 0.037394)=0.046195$, and for scenario $3, R_{144} C_{\text {scen } 3}=0.0497154$. The variation was explored for each fission product isotope by taking the relative percent difference of the base scenario 1 and that from scenario 3 (i.e., $\left(R_{j \text {, base }}-R_{j, \text { scen } 3}\right) / R_{j, \text { base }}$ *100). For the example, the isotope ${ }^{144} \mathrm{Ce}$ has a $7.6 \%$ greater relative abundance in scenario 1 compared to scenario 3. The results of this analysis are shown in Figure 3. This plot can be used to qualitatively identify those isotopes that could be most useful in gamma-ray monitoring to detect the fuel changes used in the operational scenarios being investigated with TRANSFORM. In addition, even though a particular isotope does not show a large variation, it may still be useful. An isotope that has a strong photon signature that can be routinely detected and has minimal variation (e.g., ${ }^{99} \mathrm{Mo}$ ) in $R$ lends itself to use as a base normalization (the denominator) in an isotope ratio analysis. Alternatively, isotopes that show large variation in $R$ for various fission sources could be the numerator in a proposed isotope ratio analysis.

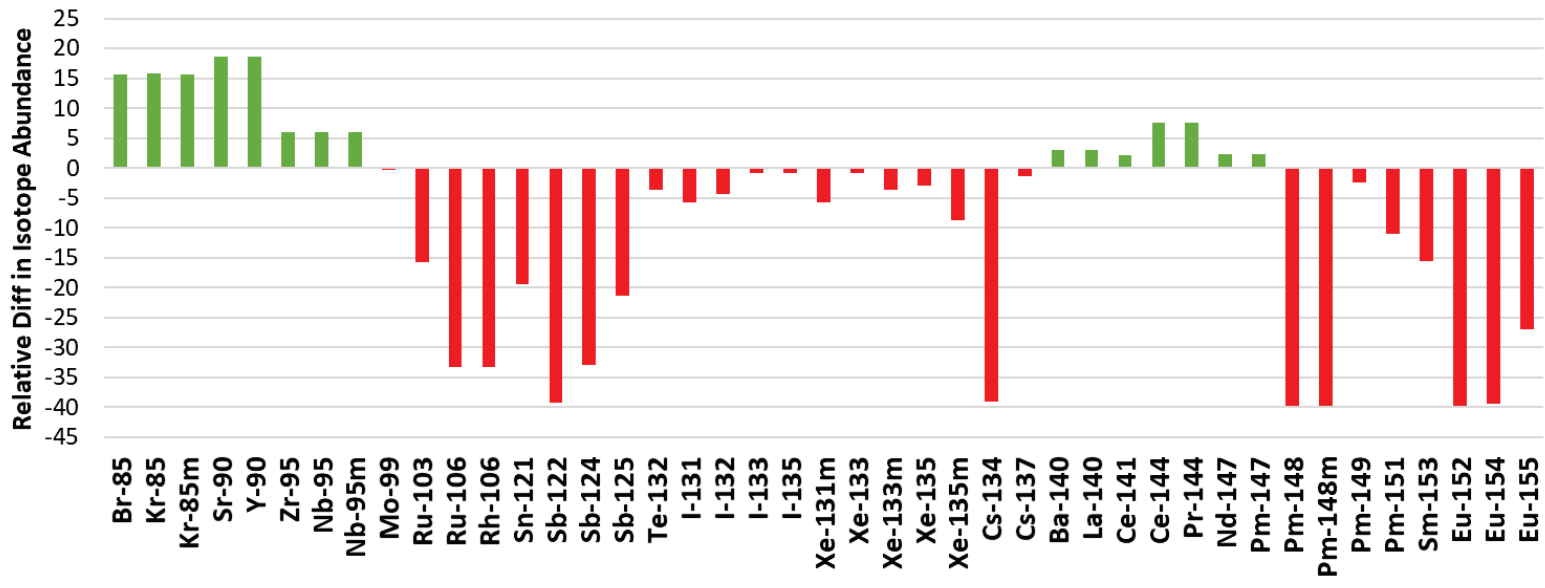

Figure 3. The relative difference of the isotope cumulative fission yields comparing the base scenario (50\%$50 \%$ thermal fission split) to scenario $3(\mathbf{7 0 \%}-\mathbf{3 0} \%$ thermal fission split). Isotopes that show a difference greater than about $5 \%$ will most likely be the best candidate isotopes that could be indications of operational changes.

\subsection{GENERALIZED ISOTOPIC CONCENTRATIONS}

Following the nuclear data analysis in Section 4.1, a study of the trends of the isotope concentrations and the power generated in the three operational scenarios was performed. As mentioned, all three scenarios should demonstrate the exact same trends up to the midpoint of the model time $(90 \mathrm{~d})$, when perturbations were introduced in scenarios 2 and 3 . The power calculated by the model for the three scenarios is shown

\footnotetext{
* The amount of isotope produced also depends on the number of fissions. This calculation is based on production per fission.

$\dagger$ The cumulative fission yield can be generalized as the amount (number of atoms) of a fission product after specified time after the fission has occurred. This is different than the independent fission yield.
} 
in Figure 4. The power curves have been normalized by their respective maximum values to show their variation with respect to each other. After the initial spike and stabilization, the reactor reaches equilibrium until the perturbation is performed at $90 \mathrm{~d}\left(0.78 \times 10^{7} \mathrm{~s}\right)$. The reactivity insertion generates another power spike in the model, which quickly smooths out as equilibrium is regained. The power change from the reactivity insertion is greater than the compositional change but both show an increase in power compared to scenario 1 . The net reactivity in scenario 2 increased which would result in a power increase. The power increase due to the fission composition change provides a further investigation into how the amount of fission products produced are impacted. TRANSFORM uses a point kinetics reactor model which does consider delayed neutron production per fission product. Since, the delayed neutron yield per fission is greater for ${ }^{235} \mathrm{U}$ compared to ${ }^{239} \mathrm{Pu}(0.0165$ and 0.0063 , respectively [12]), the change in fission composition is coupled to reactor power and neutron production. So, the behavior observed shows the coupling between fission product production and delayed neutron yield in the model. Further, investigation of the isotope activity concentrations can be useful to observe which isotopes show the largest response to the model perturbations.

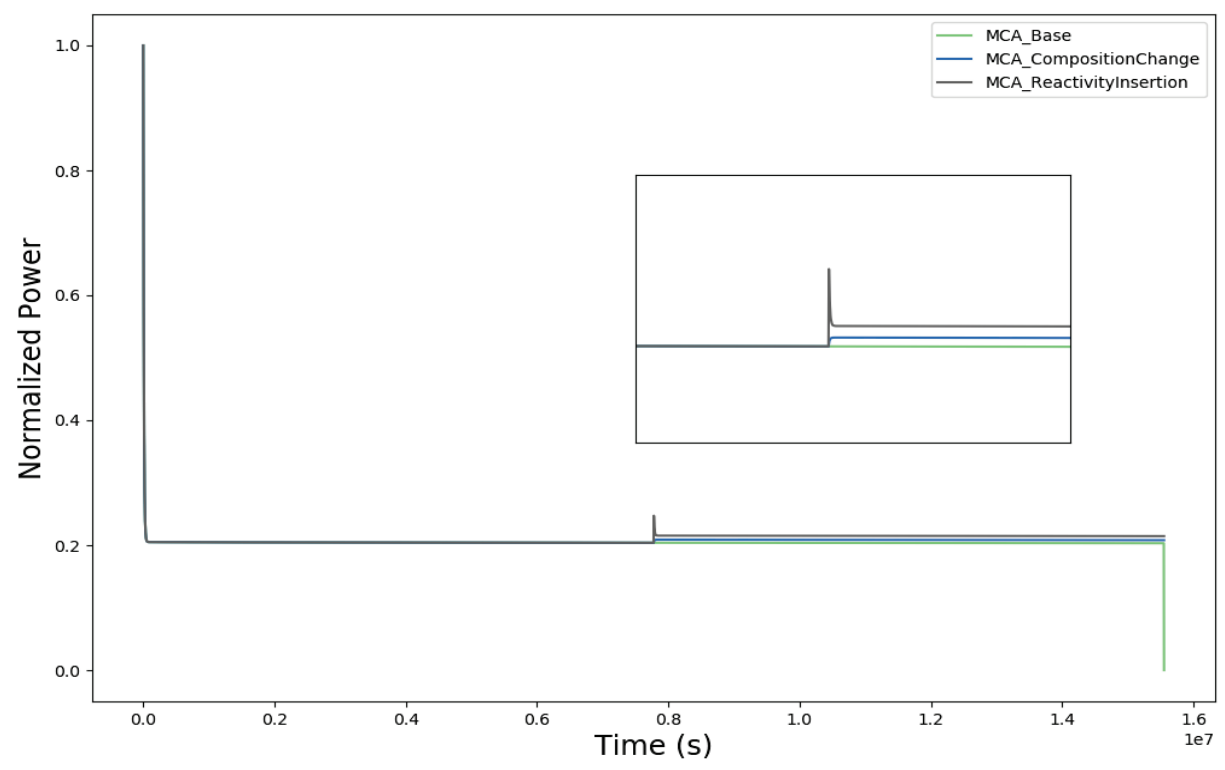

Figure 4. Normalized power of the three scenarios. The early spike is expected as the reactivity and point kinetics calculation stabilizes.

The isotopes were grouped by elemental behavior (group 1 comprises rare earth metals: $\mathrm{La}, \mathrm{Ba}, \mathrm{Ce}, \mathrm{Pr}, \mathrm{Nd}$, $\mathrm{Pm}, \mathrm{Sm}, \mathrm{Eu}, \mathrm{Gd}$ ) and/or their decay chain (group 2: Cs, Xe, I, Kr, and Br), (group 3: Sr, Y, Zr, and Nb), and (group 4: Mo, Tc, Ru, Rh, Pd, Sn, Sb, and Te). The normalized activities for group 1 in the primary fuel loop pipe from the reactor core to the PHX for the three scenarios are shown in Figure 5. In scenario 1 (Figure 5A), the isotopes demonstrate expected behavior as the decay chains come into equilibrium - driven by production and feed from precursors and reduced by decay of the isotope. For example, considering the two half-life extremes, the shortest half-life is ${ }^{151} \mathrm{Pm}$ at $28.4 \mathrm{~h}$, and ${ }^{152} \mathrm{Eu}$ is the longest-lived isotope with a half-life of $13.5 \mathrm{y}^{2}$. The ingrowth behavior follows directly from the respective half-life with shorter lived isotopes achieving equilibrium quickly, whereas the longer-lived isotopes never reach equilibrium on the time scale for the model investigated here. The more interesting behavior is observed at the midpoint when reactivity is inserted (Figure 5B) and the fission composition is changed (Figure 5C). Considering the insertion of reactivity, the shorter-lived isotopes demonstrate the largest perturbation as the reactivity has

\footnotetext{
${ }^{2}$ Note that ${ }^{144} \operatorname{Pr}$ has the shortest half-life, $17.3 \mathrm{~m}$, but it is in transient equilibrium with its parent ${ }^{144} \mathrm{Ce}$, which has a
} half-life of $285 \mathrm{~d}$ 
increased and essentially produces more of those isotopes respectively. The longest-lived isotopes do not demonstrate any observable behavior. This is because the reactivity insertion is not significant enough to drastically change their activity. However, the atom concentration would obviously be noticeable if plotted, but this study considers nondestructive radiometric assay techniques dependent on radioactivity. The intermediate isotopes $\left({ }^{140} \mathrm{Ba} / \mathrm{La},{ }^{141} \mathrm{Ce}\right.$, and $\left.{ }^{148 \mathrm{~m}} \mathrm{Pm}\right)$ do show some evidence of response to the reactivity insertion as a small bump of activity is observed while slowly recovering to the trend observed prior to reactivity insertion. Finally, considering scenario 3 , where the fission composition is changed from $50 \%-$ $50 \%{ }^{235} \mathrm{U}-{ }^{239} \mathrm{Pu}$ thermal fission to $70 \%-30 \%{ }^{235} \mathrm{U}-{ }^{239} \mathrm{Pu}$ thermal fission, very noticeable deviations in the isotope activities are found (Figure 5C). Qualitatively, consider the results contained in Figure 3, which provides the relative difference in the weighted cumulative fission yields comparing the base case to the composition change. Therefore, isotopes that have a negative relative difference (e.g., ${ }^{148,148 \mathrm{~m}, 149,151} \mathrm{Pm}$, ${ }^{153} \mathrm{Sm}$, and ${ }^{152,153,154} \mathrm{Eu}$ ) will exhibit reduced activity trends after the composition change. Generally, this is what is observed besides the longer-lived isotopes of $\mathrm{Eu}$, which not only are longer lived but have low cumulative fission yields. Vice versa, isotopes that have positive relative differences should show an increase in their activity concentration. This is shown by the curves of ${ }^{140} \mathrm{La}$ and ${ }^{144} \mathrm{Pr}$. The isotopes of groups 2, 3, and 4 are shown in the scenario groupings in Figure 6, Figure 7, and Figure 8, respectively. The trends described above for the group 1 isotopes through the three scenarios are demonstrated and observed in the group 2, 3, and 4 isotopes.
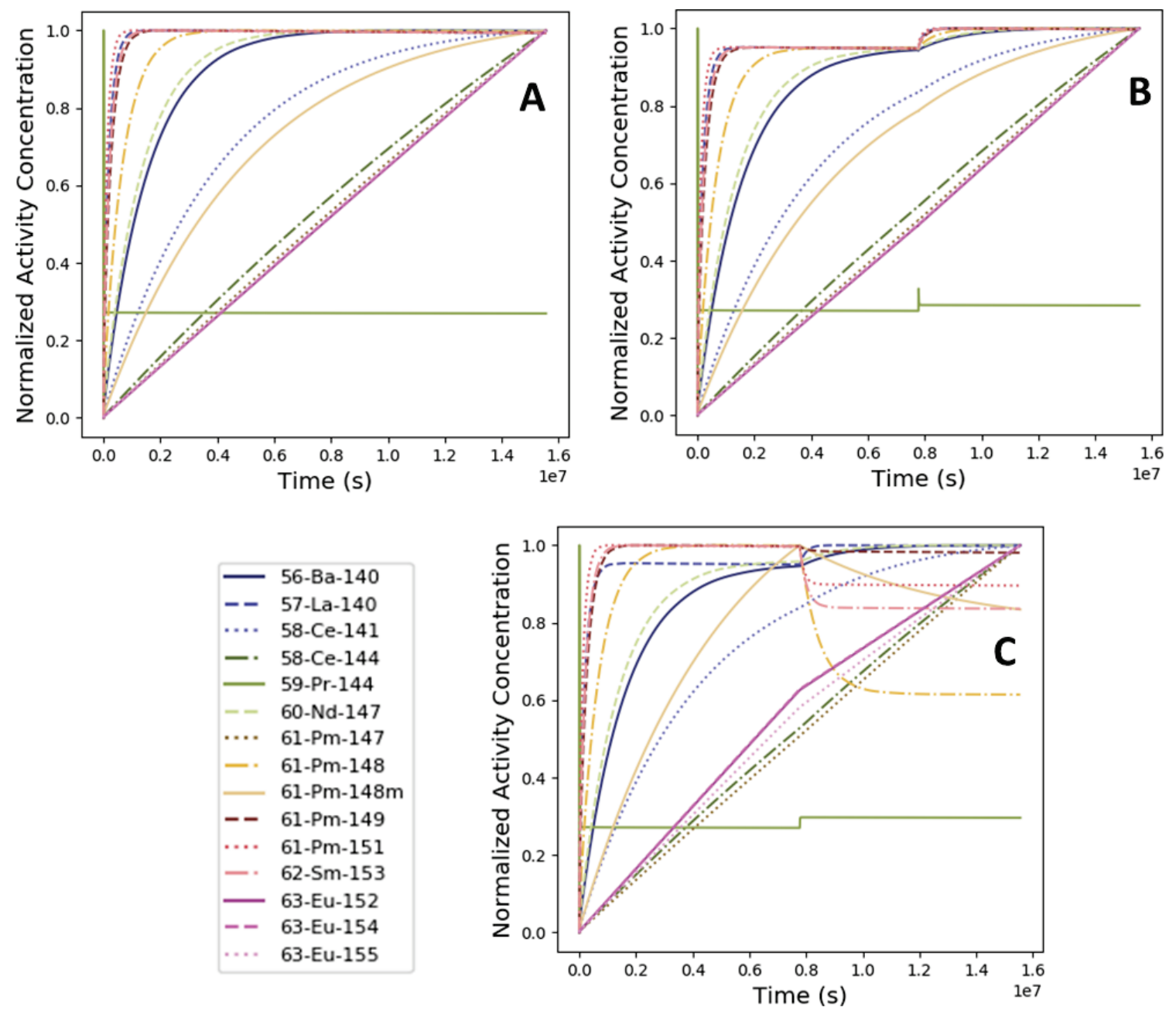

Figure 5. Normalized activities for the rare earth elements, group 1, for the three scenarios for the pipe from the reactor core to the PHX. (A) scenario 1, (B) scenario 2, and (C) scenario 3. 

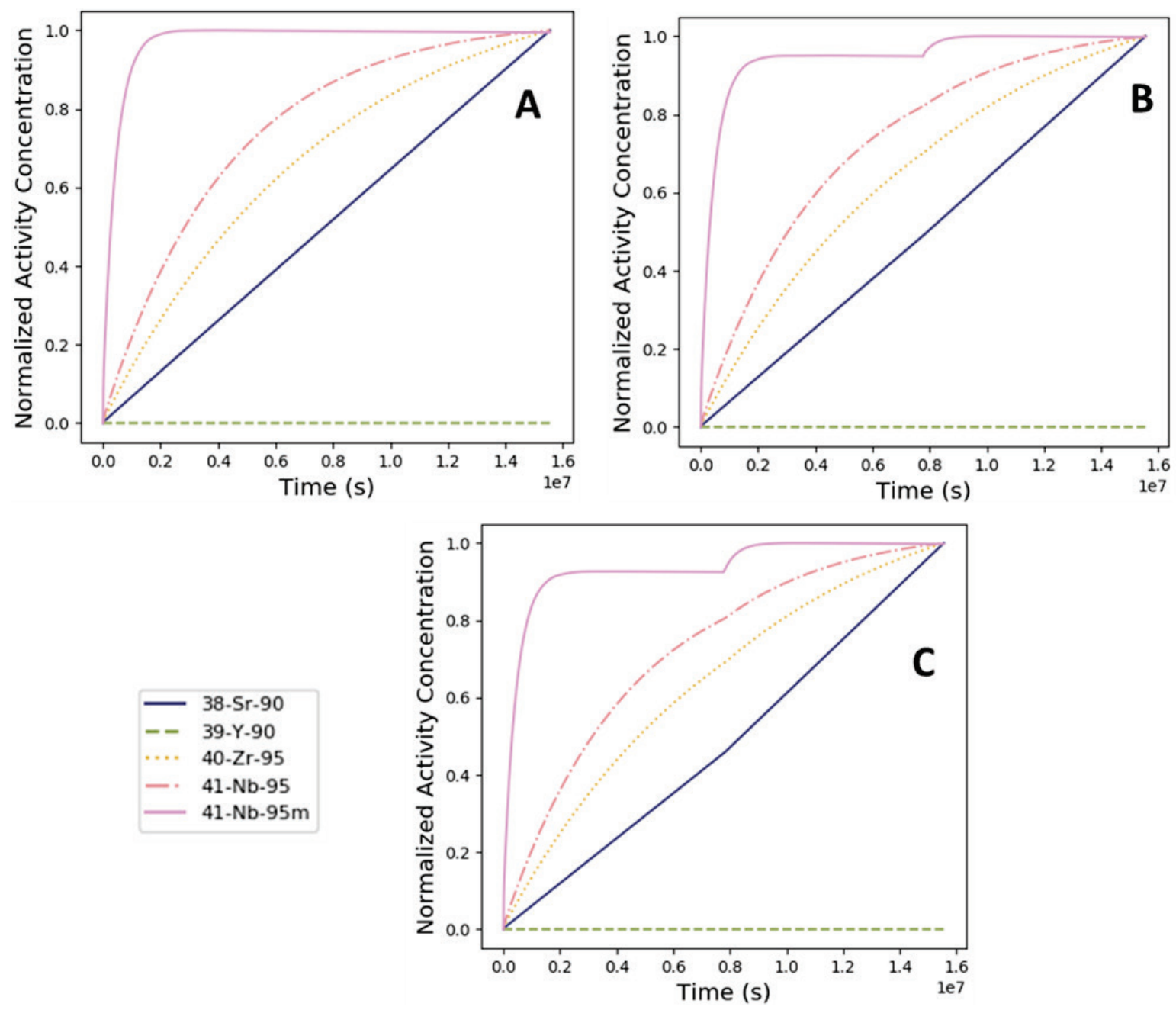

Figure 6. Normalized activities for $\mathrm{Sr}, \mathrm{Y}, \mathrm{Zr}$, and $\mathrm{Nb}$, group 2, for the three scenarios for the pipe from the reactor core to the PHX. (A) scenario 1, (B) scenario 2, and (C) scenario 3. 

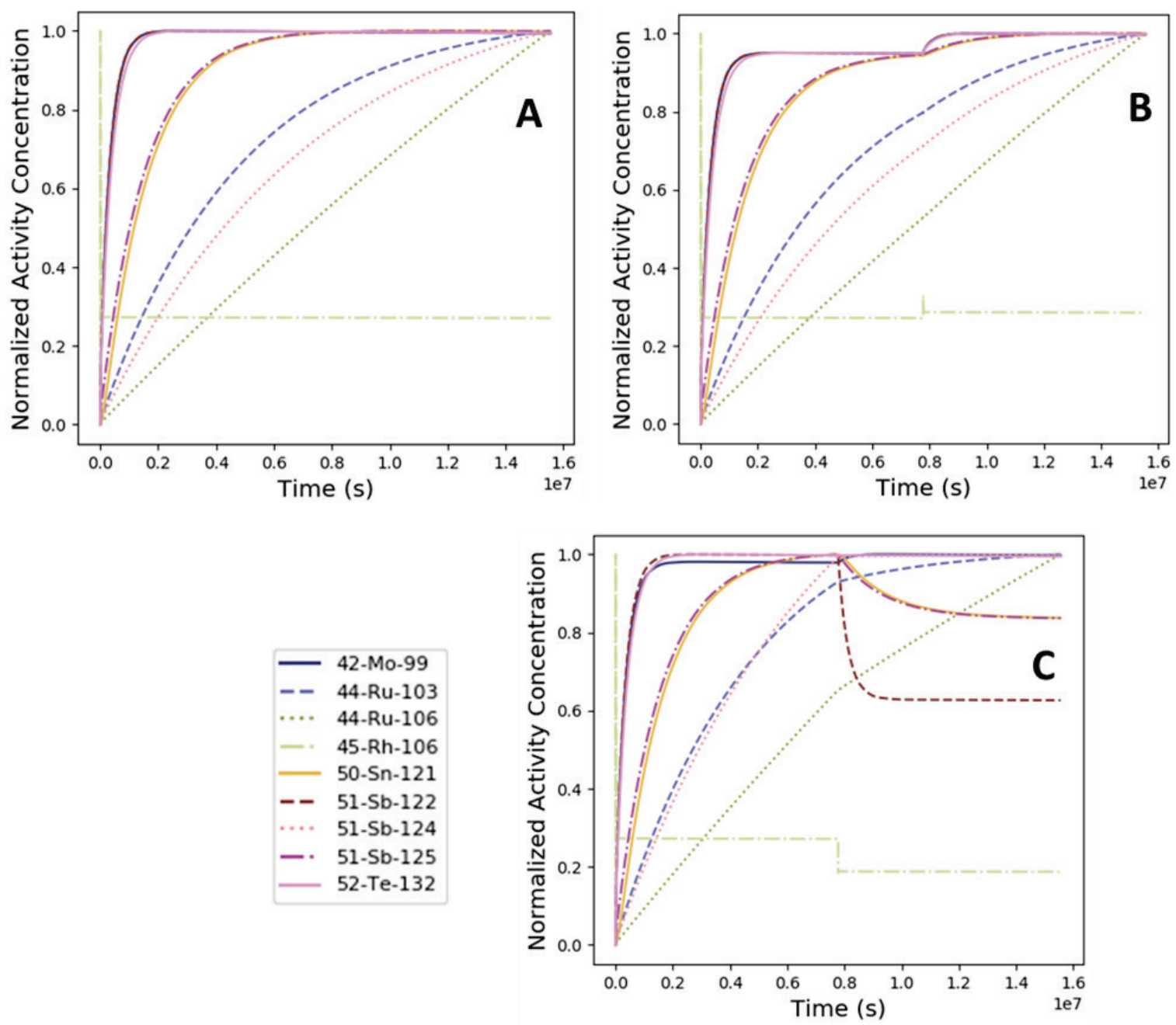

Figure 7. Normalized activities for Mo, Ru, Rh, Sn, Sb, and Te, group 3, for the three scenarios for the pipe from the reactor core to the PHX. (A) scenario 1, (B) scenario 2, and (C) scenario 3. 

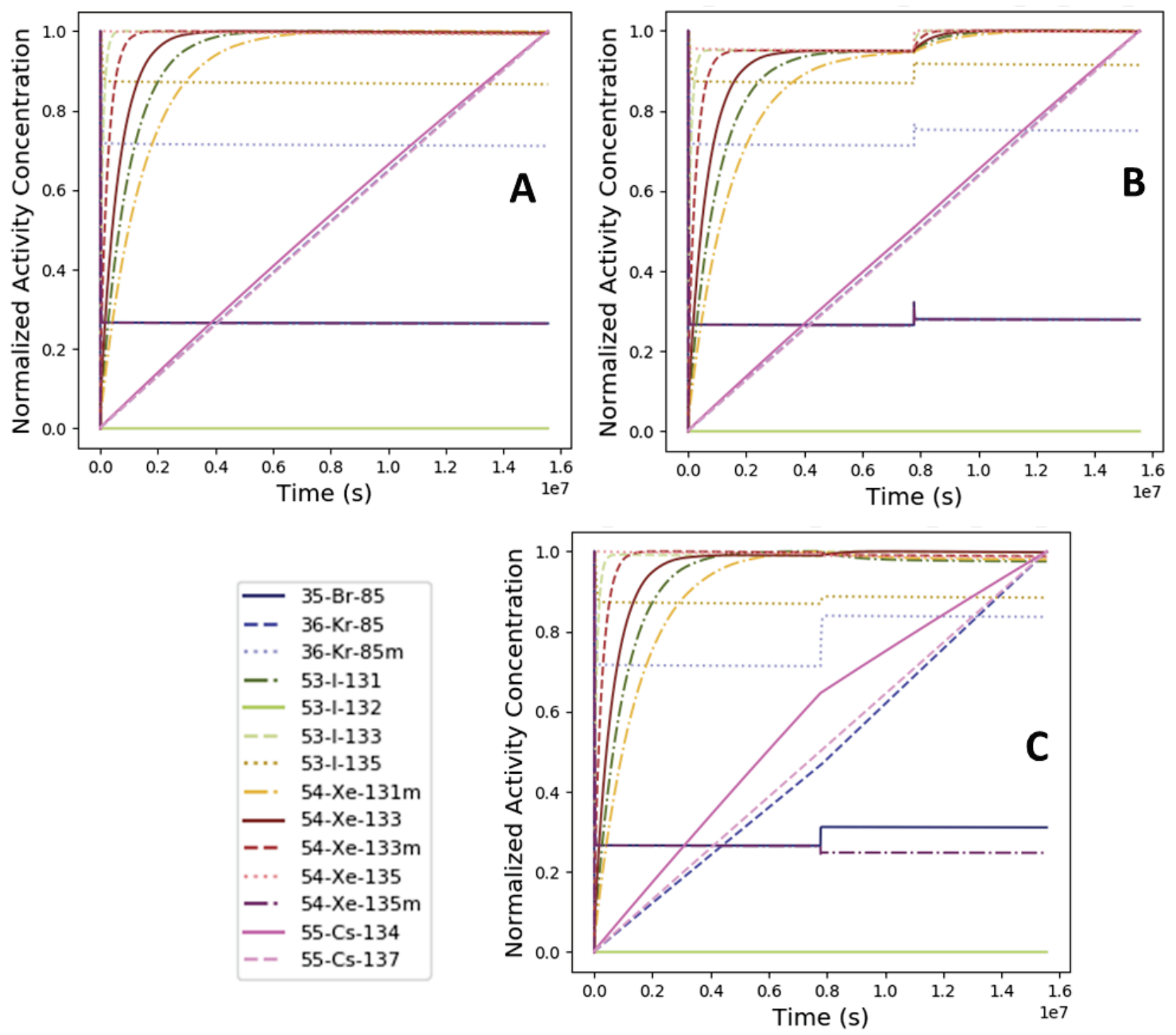

Figure 8. Normalized activities for the noble gases, $\mathrm{I}, \mathrm{Br}$, and $\mathrm{Cs}$, group 4, for the three scenarios for the pipe from the reactor core to the PHX. (A) scenario 1, (B) scenario 2, and (C) scenario 3.

\subsection{GADRAS GAMMA-RAY SPECTRA AND RESPONSE}

The GADRAS API allows synthetic spectra to be rapidly generated and enables the use of the many builtin tools. These tools include isotope identification, single/multiple regression techniques, and model fitting (using individual peaks or the full spectrum). These analyses are expedited and generally require 1 min of analysis time per spectrum. Photon energy spectra were generated for each time step based on the model geometry described in Section 3.2.1 for each of the scenarios. An example of the generated synthetic spectra is given in Figure 9 for the three scenarios at the 2,170 h time point in the model. Any specific changes in photon count rates and the attribution to a change in isotope concentration are difficult to observe directly in the energy spectrum, but general changes can be expressed by calculating the total photon count rate of each energy spectrum. This analysis is shown in Figure 10, where the total photon count rate for each $1 \mathrm{~h}$ time step in the model has been calculated for the three scenarios. The data is shown as the relative difference of the total photon count rate of the two perturbed scenarios (reactivity and composition change) to the base case. The three scenarios are nearly identical up to the perturbation to the model at the midpoint in time $(2,160 \mathrm{~h})$. The reactivity insertion results in a $\approx 4.5 \%$ increase in total photon count rate, but the composition change results in $\mathrm{a} \approx 2.5 \%$ increase in total photon count rate. The increase in total count rate is expected because both scenarios resulted in an increase in power calculated in the model as shown in Figure 4 because the power (i.e., fissions per unit time) is directly related to the 
amount of each fission product isotope produced. Therefore, radiometric measurements of total photon flux could be used to monitor total reactor power and the equilibrium/operational state of the MSR. However, as observed in these two scenarios, it would be impossible to distinguish a reactivity change from a composition change by solely monitoring the total photon energy spectrum. Therefore, methods discussed previously, using ratios of photon peaks measured continuously could be used to further investigate any changes to the gross photon count rate. Because the isotope's activity is directly related to its fission yield, changes to the fission composition could be found through a ratio analysis of specific photon peak count rates, which would provide a method to distinguish a power increase from a compositional change. This could be extremely useful to understand how the fuel composition of the MSR changes over time, resulting in a method to understand production of ${ }^{239} \mathrm{Pu}$ in the $\mathrm{U}$ fuel cycle.

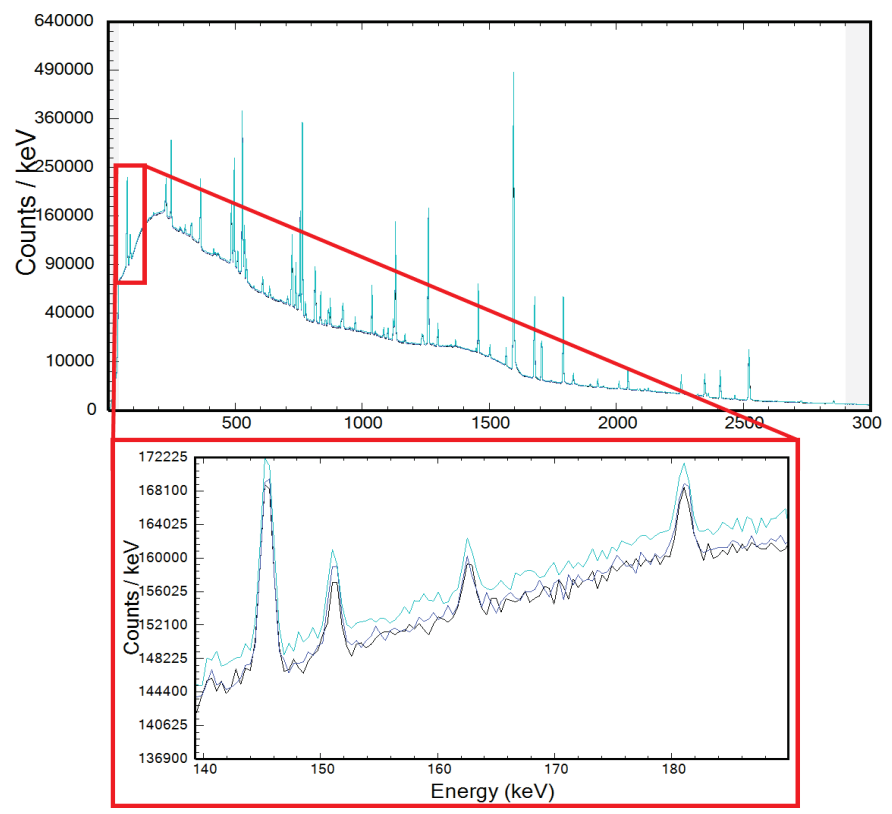

Figure 9. Synthetic photon spectra for the three scenarios ( 1 is black, 2 is teal, and 3 is blue). Differences in the spectral count rate are visible in the close-up of the low-energy portion of the spectra.

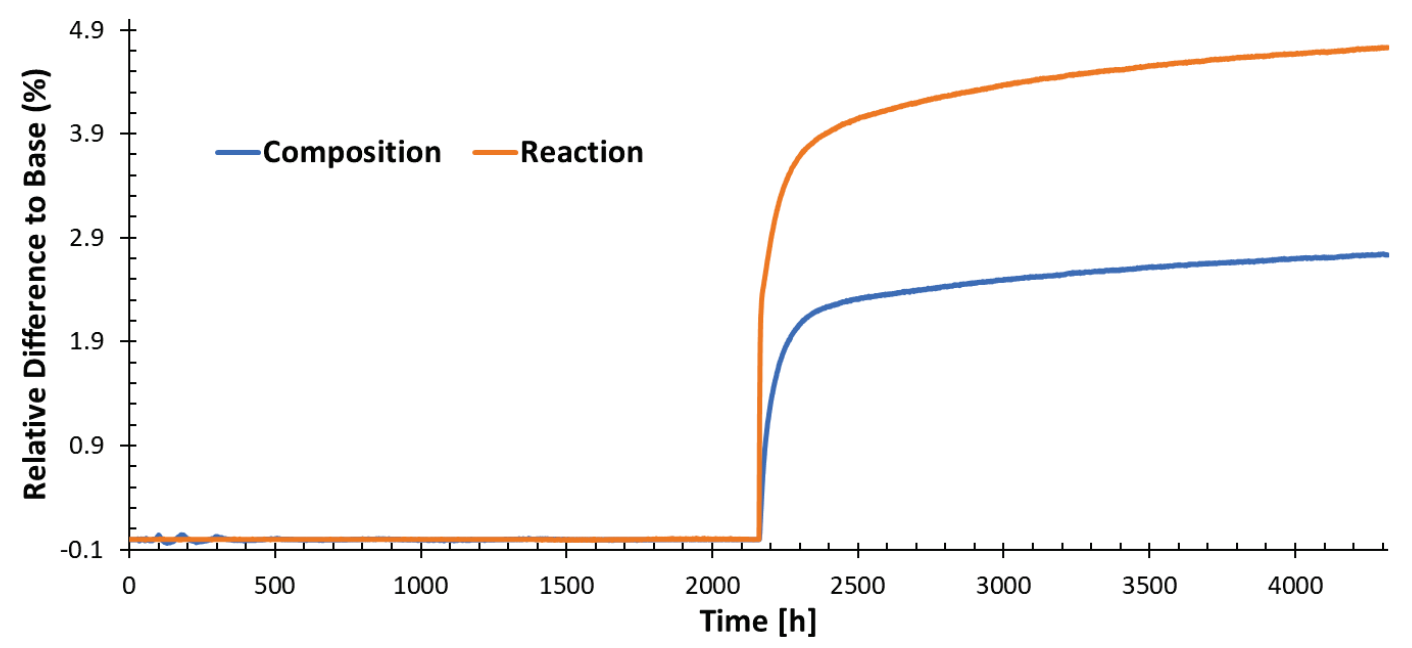

Figure 10. Relative difference of photon count rate comparing scenarios 2 and 3 to scenario 1 . The variation due to the reactivity insertion and composition change is clearly seen at 2,160 hours. The photon count rate changes from about $2 \%$ for the composition change and $4.5 \%$ for reactivity insertion of $10 \mathrm{pcm}$. 


\subsubsection{Photon Peak Tracking Example}

A method using the GADRAS peak fitting routing was implemented in the API. Each fission product isotope was associated with its respective photon signature(s) and stored in a lookup table. Photons with energies less than $30 \mathrm{keV}$ and with an intensity less than $0.01 \%$ were excluded because their impact to the measured spectra within this geometry will be minimal. The fitting routine was applied to each synthetic gamma-ray spectra for each time step for the three case scenarios. The fitting routine returns the photon peak energy, count rate, uncertainties, etc. From the peak fitting results the routine then associates the identified peaks, within a user defined tolerance, to a given isotope and tracks those count rates for each spectrum processed. This method was applied to the three scenarios modeled using TRANSFORM excluding the stable isotopes and other isotopes that would not contribute to the gamma-ray spectra (e.g., $\left.{ }^{3} \mathrm{H},{ }^{4} \mathrm{He}\right)$. The output of the analysis is a time trend of each peak's count rate grouped with the associated radioisotope. The results of this analysis are given for two isotopes: ${ }^{99} \mathrm{Mo}$ and ${ }^{140} \mathrm{La}$ in Figure 11 and Figure 12, respectively. The top five photon emissions that contribute to the peak tracking results are shown however, several other photon lines were included in the lookup table. Three plots are given for each isotope for the results of each scenario and the peak tracking results: A is the base case (scenario 1), $\mathrm{B}$ is the reactivity insertion (scenario 2), and $\mathrm{C}$ is the change is fission composition (scenario 3 ). The base case plots for both isotopes produce expected results - mainly as the reactivity/power of the model come to equilibrium (around $100 \mathrm{~h}$ ), the gamma-ray peak counts show little variation over time. There is a slight decrease in counts over time for both isotopes, and this is probably an artifact of counting statistics in the spectrum and other artifacts from the peak fitting algorithm in GADRAS. In addition, the concentrations of ${ }^{99} \mathrm{Mo}$ and ${ }^{140} \mathrm{La}$ for scenario 1 show very constant trends after equilibrium (Figure 7 and Figure 5, respectively), but other isotopes in the simulation slowly build in concentration. The isotopes that are growing in could be contributing to the Compton continuum of the gamma-ray spectrum and changing the background, making the peaks of the isotopes that have a constant concentration appear to be decreasing in peak counts. Further analysis of the spectra will be performed to understand all the factors contributing to the trends in the peak tracking results.

The peak tracking results for scenario 2, where reactivity was inserted into the model, also shows results as expected. The increase in reactivity is an increase in reactor power and therefore an increase in fissions. Therefore, there should be an increase in the amount (activity) of the isotopes present in the GADRAS model that generated the synthetic spectra. This trend is observed for the dominant photon lines of ${ }^{99} \mathrm{Mo}$ and ${ }^{140} \mathrm{La}$ and the majority of the other isotopes investigated. Note, some isotopes (e.g., ${ }^{103} \mathrm{Ru},{ }^{152} \mathrm{Eu}$ ) demonstrated a decrease in photon peak counts at the point of reactivity insertion. This is most likely because these isotopes had not come into decay chain equilibrium (or never may have equilibrium) so inserting reactivity results in a reset to the time decay kinetics of the respective decay chain may potentially reduce that isotopes activity. See Figure 7 for the concentration trend of ${ }^{103} \mathrm{Ru}$ and Figure 5 for ${ }^{152} \mathrm{Eu}$.

Finally, the peak tracking results for the fission composition change in scenario 3 are given in ' $\mathrm{C}$ ' in Figure 11 and Figure 12. The dominant photon peak at $529 \mathrm{keV}$ of ${ }^{99} \mathrm{Mo}$ shows a very minor positive variation while the dominant photon peak at $1,596 \mathrm{keV}$ of ${ }^{140} \mathrm{La}$ shows a larger positive change almost equivalent to the reactivity insertion. These changes can be understood by studying the relative differences of these isotope's cumulative fission yields as given in Figure 3. Molybdenum-99 has a very small negative offset $(-0.34 \%)$ from the base case fission composition compared to the composition change inflicted in scenario 3. This small offset is not significant enough to largely change the results but there is a small positive offset visible. This could be due to a combined effect and the influence of other isotopes on the gamma-ray spectrum. The larger offset observed for ${ }^{140} \mathrm{La}$ is consistent with the positive difference of $3 \%$ found in the analysis given in Figure 3. Only considering the photon peak count trends, it would be very difficult to distinguish the difference in scenario 2 from 3 . Using ${ }^{140} \mathrm{La}$, the obvious conclusion would be that an increase in power has caused the change. However, since the trends observed 
for ${ }^{99} \mathrm{Mo}$ are different for the perturbation imposed in scenarios 2 and 3, its relative difference in fission yield composition is small. Coupled with a dominant photon peak, this would support using this isotope as the normalization isotope in a ratio analysis. Therefore, these two scenarios could possibly be distinguished by analyzing the ratio of the photon peak count rates of the $1,596 \mathrm{keV}$ photon of ${ }^{140} \mathrm{La}$ to the $529 \mathrm{keV}$ photon of ${ }^{99} \mathrm{Mo}$ (i.e., ${ }^{140} \mathrm{La} /{ }^{99} \mathrm{Mo}$ ). This data is given in Figure 13 and is a very interesting result because it does demonstrate the sensitivity of online gamma-ray spectral measurements to changes in reactivity and fission composition change. These are preliminary results that could be lacking important details that could influence a "real" experimental measurement, but conceptually the ability to use a ratio analysis to understand and classify perturbations to a system to indicate potential diversion or misuse of material is a strong and motivational result.
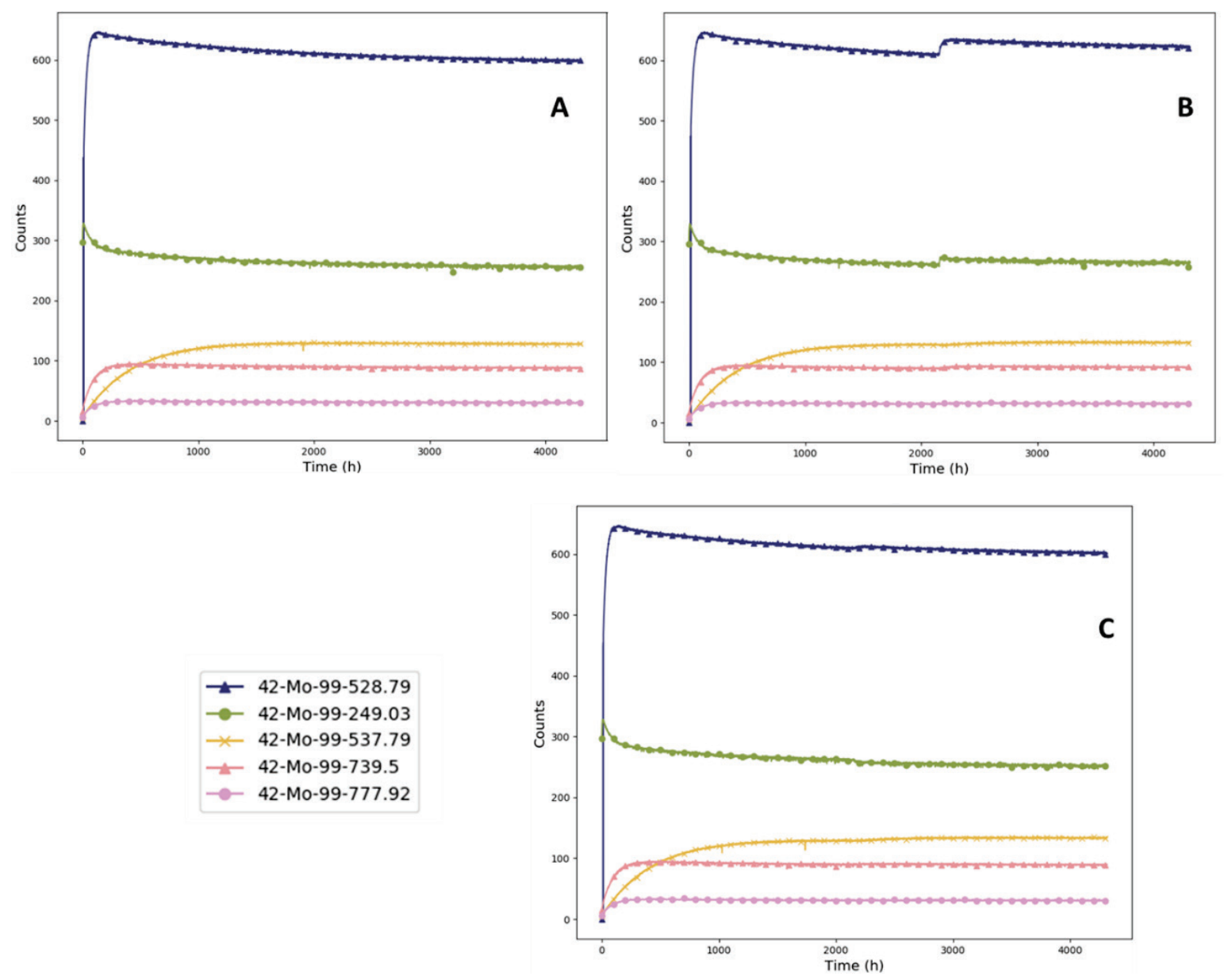

Figure 11. Photon peak counts resulting from the peak tracking GADRAS analysis for ${ }^{99} \mathrm{Mo}$. The three scenarios for the isotope concentration in the pipe from the reactor core to the PHX are shown for (A) scenario 1, (B) scenario 2, and (C) scenario 3. 

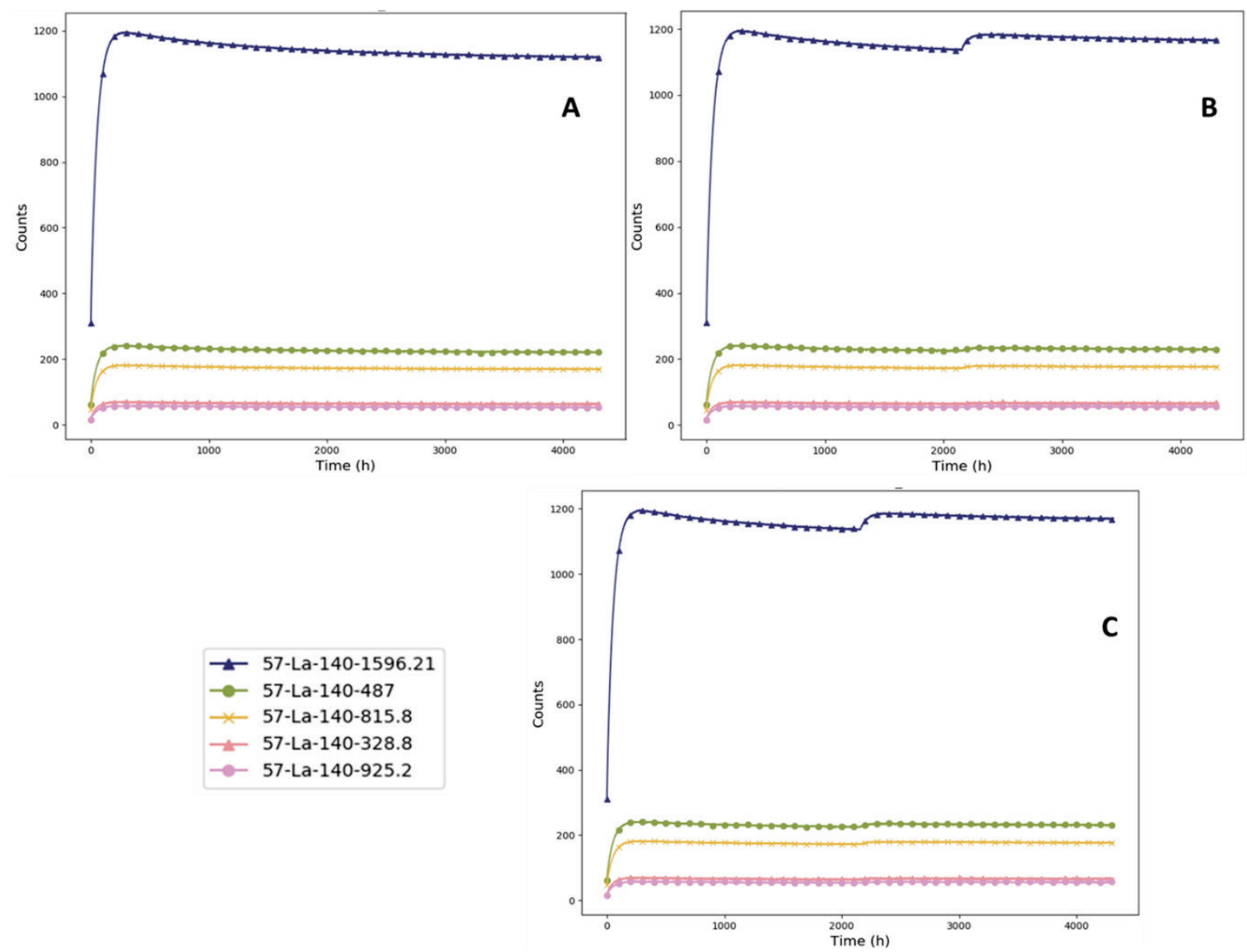

Figure 12. Photon peak counts resulting from the peak tracking GADRAS analysis for ${ }^{140} \mathrm{La}$. The three scenarios for the isotope concentration in the pipe from the reactor core to the PHX are shown for (A) scenario 1,

(B) scenario 2, and (C) scenario 3.

\subsection{GEANT4 GAMMA-RAY SPECTRA RESULTS}

The geometry for the Geant 4 synthetic spectral simulations was developed to investigate the noble gas and volatile (i.e., halogen) isotopes. The fission product isotope activities were taken from the primary fuel pipe from the reactor core to the PHX. This analysis assumed the ability to either extract a separated sample of these elements from the fuel salt or provide some insight to monitoring a reactor off-gas system. Most vendor designs have an off-gas system in place to (mainly) remove ${ }^{135} \mathrm{Xe}$ from the primary fuel loop. Xenon-135 is a reactor poison because it has a thermal

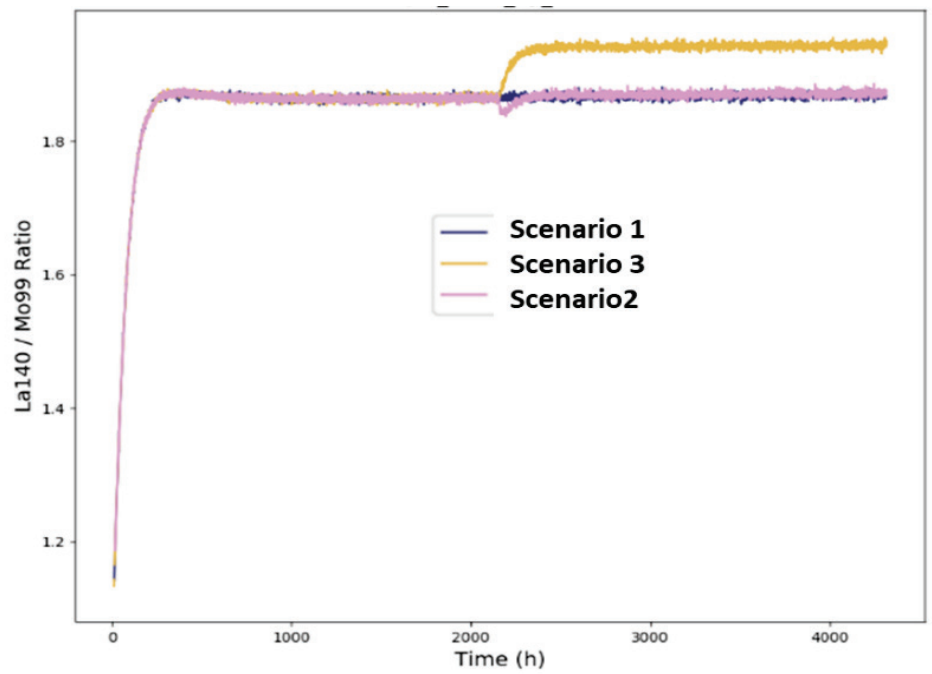

Figure 13. Ratio of the $1,596 \mathrm{keV}$ peak counts of ${ }^{140} \mathrm{La}$ to the $529 \mathrm{keV}$ photon peak counts of ${ }^{99}$ Mo for the three scenarios. neutron absorption cross section, $\sigma(n, \gamma)$, of $2.6 \times 10^{6}$ barns. To compare the three scenarios, the fission product activities were used from the base 
case (scenario 1) at $89.58 \mathrm{~d}$, and from scenario 2 and 3 at $90.08 \mathrm{~d}$ (there is no need to evaluate scenarios 2 and 3 before the $90 \mathrm{~d}$ perturbation point as the activities will be identical to scenario 1).

A Cu ampule with wall thickness of $0.5825 \mathrm{~cm}$, length of $4.06 \mathrm{~cm}$, and radius of $0.6 \mathrm{~cm}$ was placed $2 \mathrm{~m}$ from a HPGe detector and contained the homogenously distributed fission product activities. The activities were scaled down from their activities in the primary fuel pipe from the TRANSFORM solution based on the volumetric ratio comparing the pipe to the ampule. The scaling was performed to reduce the most abundant isotope to $1 \times 10^{7}$ decays but maintain the relative variation among the isotopes. After scaling, only isotopes with greater than $1 \times 10^{5}$ were simulated. The number of decays generated for each isotope for simulation are given in Figure 14.

- Scenario 1 Scenario 2 Scenario 3

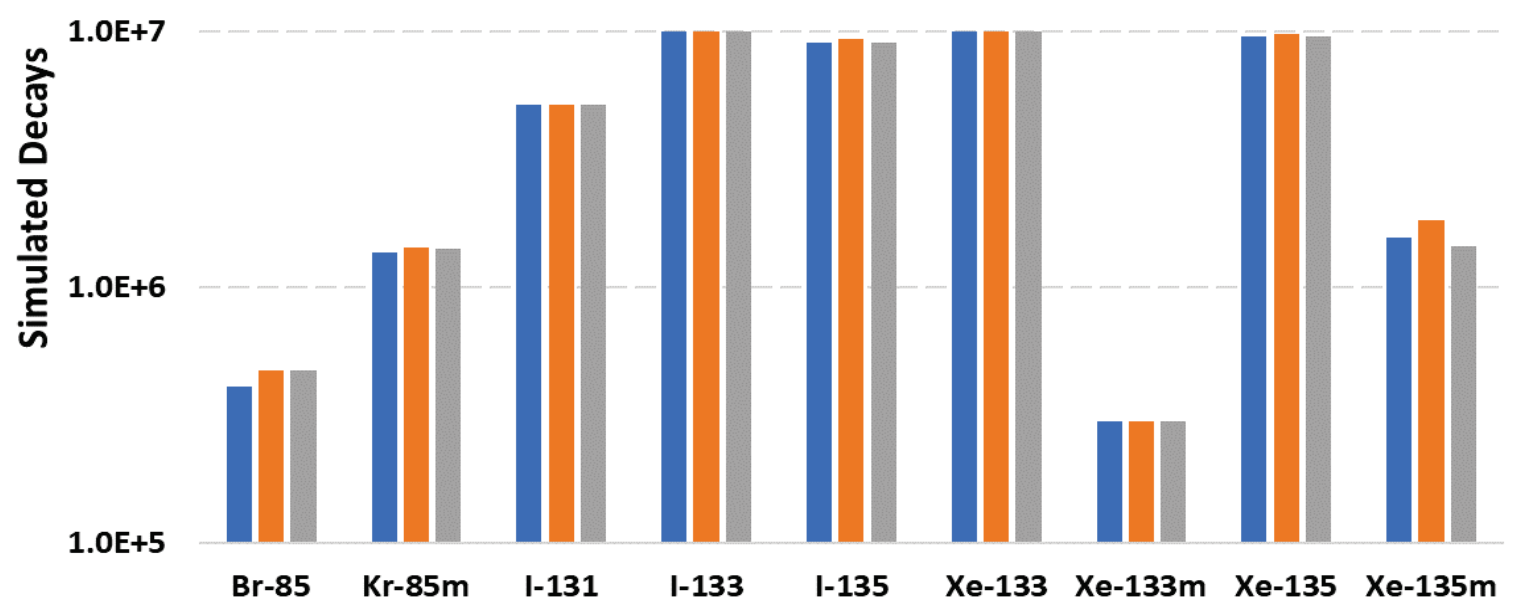

Figure 14. Simulated number of decays for the fission product isotopes after downscaling the activities from the primary fuel circuit. The activities were taken before the perturbation for scenario 1 and after the perturbation for scenarios 2 and 3. Generally, the largest differences found are the activities for ${ }^{85} \mathrm{Br}$ and ${ }^{135 m} \mathrm{Xe}$.

A separate simulation for each isotope was performed and the energy deposited in the HPGe detector was saved for further analysis. A Python script processed each data file per isotope and created a histogram. The generated histograms for each scenario were added for the nine isotopes and then broadened with a functional response of a typical HPGe high resolution detector. The broadened histograms are overplotted in Figure 15. The dominant photon peaks are at $151\left({ }^{85 \mathrm{~m}} \mathrm{Kr}\right), 250\left({ }^{135} \mathrm{Xe}\right), 364\left({ }^{131} \mathrm{I}\right), 526\left({ }^{135 \mathrm{~m}} \mathrm{Xe}\right), 530$ $\left({ }^{133} \mathrm{I}\right), 546\left({ }^{135} \mathrm{I}\right)$, and $1,131 \mathrm{keV}\left({ }^{135} \mathrm{I}\right)$. Noticeable gamma-ray peaks are present where there are deficiencies from the simulation of a scenario, which suggests there is potential to use high resolution measurements of the reactor off-gas system to identify operational conditions. These deficiencies should correlate with the model parameters that dictate the fission product activities and propagate through to the number of decays used for each isotope in the Geant 4 simulation, shown in Figure 14. As an example, the $1,000 \mathrm{keV}$ region is given in Figure 16. The $1,131 \mathrm{keV}$ gamma-ray is emitted by ${ }^{135} \mathrm{I}$ with $23 \%$ intensity. The statistics in this region are low but the general trend observed for this peak does follow the TRANSFORM results that show an increase in the ${ }^{135}$ I activity from scenario 2 . The activity increase of ${ }^{135} \mathrm{I}$ is apparent in Figure $8 \mathrm{C}$ following the perturbation to the model at $90 \mathrm{~d}$. In addition, a similar photon peak ratio analysis could be performed as discussed in Section 4.3.1. Future work will perform a more detailed analysis with the addition of increasing the number of decays in the model to generate more statistics in the detector response histograms. 


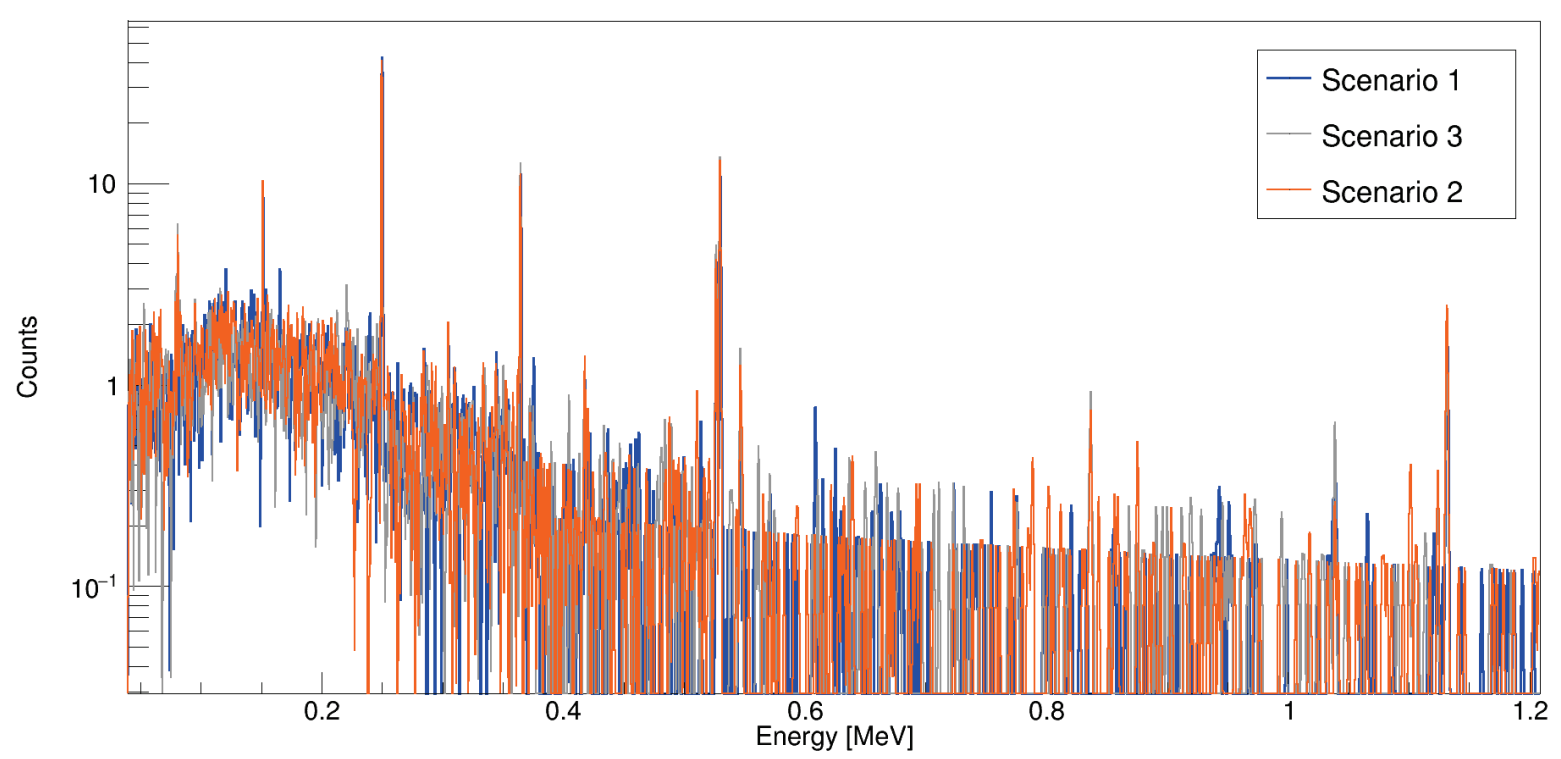

Figure 15. Energy broadened histograms of the three scenarios after physics transport modeling with Geant4.

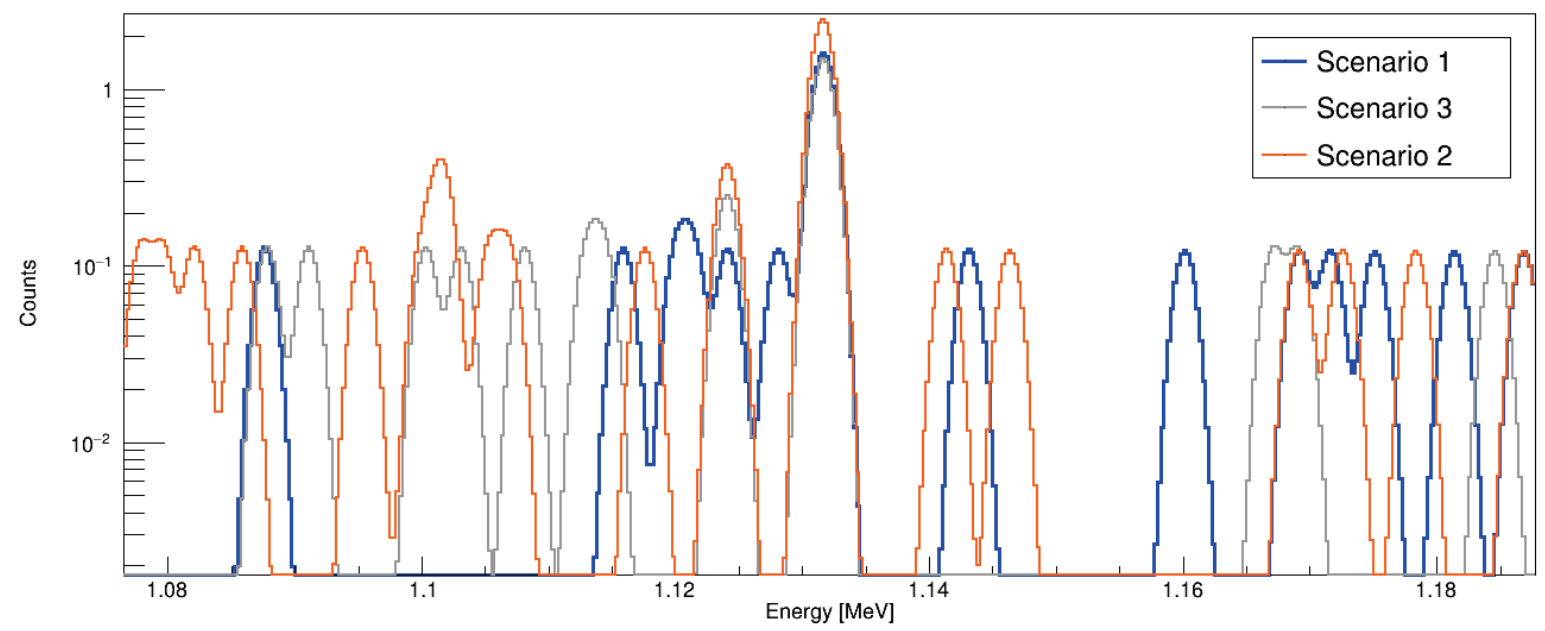

Figure 16. Close-up of the region around $1,000 \mathrm{keV}$ in Figure 15 and the $1,131 \mathrm{keV}$ gamma-ray of ${ }^{135} \mathrm{I}$.

\section{CONCLUSIONS AND FUTURE WORK}

This report presents the analysis results of the TRANSFORM simulation of the MSDR model under three operational scenarios. Each scenario was solved for $180 \mathrm{~d}$ in $1 \mathrm{~h}$ time steps. Scenario $1 \mathrm{was}$ a base case with no changes imposed during the $180 \mathrm{~d}$, scenario 2 instantaneously injected reactivity into the model at $90 \mathrm{~d}$, and scenario 3 changed the percentage of fission composition from $50 \%-50 \%{ }^{235} \mathrm{U}-{ }^{239} \mathrm{Pu}$ to $70 \%-$ $30 \%{ }^{235} \mathrm{U}-{ }^{239} \mathrm{Pu}$ at $90 \mathrm{~d}$. The fission product activities in the fuel loop pipe from the reactor core to the PHX were used to generate synthetic gamma-ray spectra using tools developed with the GADRAS API and GEANT4. The scenario changes allowed an investigation into the sensitivity of online gamma-ray spectral measurements under the modeled operational perturbations. This research will allow a more thorough understanding of indications of changing an MSR's operating conditions and how these changes could influence online gamma-ray spectral measurements. It will also help identify how gamma-ray spectroscopy might be used in a facility's broader MC\&A program to detect changes in SNM quantities 
and identify diversion of SNM in a timely manner, which are necessary for Nuclear Regulatory Commission licensing requirements.

The reactor power for each scenario was analyzed. The power was normalized by its respective maximum value for each scenario, and a small change was observed at the $90 \mathrm{~d}$ time step when the perturbation to the simulation was introduced. The insertion of reactivity in scenario 2 showed a larger power change compared to changing the fission composition in scenario 3. Further, each radioisotope's activity was analyzed to understand how the fission product decay chains responded to the reactivity addition and the fission composition change. Depending on the isotope's half-life and its decay chain kinetics, either an equilibrium condition was found, or the activity steadily increased for scenario 1 and up to the midpoint of all scenarios. After reactivity was added to the model, most of the fission product isotopes showed an increase in concentration, as expected. However, when the fission composition was changed in scenario 3, the fission product isotope's activity was found to be dependent on its cumulative fission yield. Some isotopes exhibited no change, but some had a negative or positive change compared to scenario 1 .

Synthetic gamma-ray spectra were generated using the GADRAS API and Geant4. The total photon count rate is proportional to the reactor power. Therefore, the photon count rate is sensitive to changes in reactivity. This could be used to identify changes in reactivity due to refueling operations, changes in fissile mass, or control rod movement. This analytical technique provides sensitivity to reactivity changes and the source of fission (material) in the modeled reactor. However, it is not sensitive enough to uncover the mechanism of reactivity (power) change. To distinguish the cause of the photon count rate change, a photon peak count rate ratio analysis was investigated. The peak fit tracking algorithm developed with the GADRAS API was used to analyze and calculate gamma-ray count rates from the synthetic gamma-ray spectra. Dividing the peak count rates of the dominant gamma-ray of ${ }^{140} \mathrm{La}$ to ${ }^{99}$ Mo exhibited a difference that provided a way to distinguish the reactivity (or gross count rate) change from the fission composition change. The gamma-ray spectra generated using Geant4 focused only on noble gas and volatile fission product isotopes. This preliminary analysis can be used to understand the utility of monitoring a reactor's off-gas system for changes in operational conditions. This analysis found that the ${ }^{135}$ I gamma-ray at 1,131 $\mathrm{keV}$ did correlate with the expected changes of isotope activity from the fission composition change and could be a good signature to track changes in SNM and their contribution to power generation throughout reactor operation.

\section{REFERENCES}

[1] K. K. Hogue, P. Gibbs, M. P. Dion and M. Poore, "Domestic Safeguards Material Control and Accountancy Considerations for Molten Salt Reactors," Oak Ridge National Laboratory, 2021.

[2] M. S. Greenwood, B. R. Betzler, A. L. Qualls, J. Yoo and C. Rabiti, "Demonstration of the Advanced Dynamic System Modeling Tool TRANSFORM in a Molten Salt Reactor Application via a Model of the Molten Salt Demonstration Reactor," Nuclear Technology, vol. 206, no. 3, 2020.

[3] M. S. Greenwood, B. R. Betzler and A. L. Qualls, "Dynamic System Models for Informing Licensing and Safeguards Investigations of Molten Salt Reactors," ORNL, 2018.

[4] Modelica, "The Modelica Association," [Online]. Available: https://www.modelica.org/.

[5] Dassault Systemes, "Dymola Systems Engineering," [Online]. Available: https://www.3ds.com/products-services/catia/products/. 
[6] E. S. Bettis, L. G. Alexander and H. L. Watts, "Design Studies of a Molten-Salt Reactor Demonstration Plant," ORNL, 1972.

[7] M. S. Greenwood and B. R. Betzler, "Modified Point-Kinetics Model for Neutron Precursors and Fission Product Behavior for a Fluid-Fueled Molten Salt Reactor," Nucl. Sci. Eng., vol. 193, 2018.

[8] Lawrence Berkeley National Laboratory, "Modelica Buildings Library," [Online]. Available: https://simulationresearch.lbl.gov/modelica/buildingspy/.

[9] S. Agostinelli and et al., "Geant4 - a simulation toolkit," NIMA, vol. 506, 2003.

[10] A. Houtzeel and F. F. Dyer, "A Study of Fission Products in the Molten-Salt Reactor Experiment by Gamma Spectrometry," ORNL-TM-3151, 1972.

[11] M. B. Chadwick and et al., "ENDF/B-VII.1 Nuclear Data for Science and Technology: Cross Sections, Covariances, Fission Product Yields and Decay Data," Nuclear Data Sheets, vol. 112, 2011.

[12] K. O. Ott and R. J. Neuhold, Introductory Nuclear Reactor Dynamics, Americal Nuclear Society, 1985. 


(n)

